\title{
SOBRE LAS CECAS CELTIBÉRICAS DE TAḾUŚIA Y ŚEKAISA Y SU RELACIÓN CON EXTREMADURA
}

\author{
POR \\ CRUCES BLÁZQUEZ CERRATO \\ Universidad de Salamanca
}

\section{RESUMEN}

En las líneas siguientes presentamos un lote de monedas inédito procedente del castro de Villasviejas del Tamuja (Botija-Plasenzuela, Cáceres). Tradicionalmente se viene considerando este asentamiento como vetón a pesar de que ninguna ciudad vetona acuñó moneda. De ahi, la importancia de la publicación y estudio de este conjunto ya que apoya la posibilidad de que la ceca celtibérica de tamiuśia estuviera en este castro atestiguando la presencia de celtíberos en Lusitania, dato que confirman tanto los testimonios literarios como los arqueológicos.

\section{SUMMARY}

In the following text we present an unpublished lot of coins coming from the Villasviejas del Tamuja (Botija-Plasenzuela, Cáceres). Traditionally this settlement was considered vetton, but no Vetton city minted coin. That is the importance of presenting and examinating this coin ensemble; this lot of coins supports the localization of tamiusia mint in Villasviejas on the one hand, and on the other they testify the presence of Celtiberian people in Lusitania; the fact is confirmed by the literary and archaeology evidences.

\section{ANTECEDENTES}

La ciudad de tamiuśia no es citada en ninguna fuente histórica a no ser en sus monedas, donde epígrafes en carácteres ibéricos nos transcriben un topónimo indudablemente celtibérico. Este epigrafe, más su tipologia - la propia de toda la moneda de la Celtiberia - llevó a buscar la ciudad en ese territorio y con ello a denominarla tanusia y no tamísia como parece ser su nombre correcto. La rareza de sus monedas y por tanto la escasez de sus hallazgos, no permitían, hasta fechas recientes, ni perfilar más su localización ni contradecir esta opinión ge- neral '. Más aún, la tipología y la metrologia de las monedas de tamuśia encajan perfectamente con las del mundo celtibérico, concretamente con un conjunto de emisiones de diferentes ciudades que tienen como símbolo en anverso un delfin delante de la cabeza masculina y otro detrás y en el reverso el jinete lancero; la situación geográfica de estos talleres pertenecientes al llamado "grupo de los dos delfines" parecía corresponder a la parte occidental de la Sedetania, entre el Jalón y el Alto Ebro, allí donde la había supuesto situada Untermann ${ }^{2}$.

Este consenso de opinión sufre un profundo giro en 1988, cuando J. L. Sánchez Abal y S. García Jiménez publican un lote de 108 monedas de tamusía de las que 101 proceden del castro prerromano de Villasviejas del Tamuja, perteneciente a los términos municipales de Botija y Plasenzuela (Cáceres). Los autores defienden que esta ceca podría estar ubicada en dicho castro utilizando dos argumentos básicos: uno numismático, el área de dispersión de estas monedas, y otro filológico, la relación entre la leyenda del reverso (tamísía) y el topónimo del río

\footnotetext{
' Untermann, J., Monumenta Linguarum Hispanicarum, 1, 1, Wiesbaden, 1975, p. 318 (cit. en adelante como MLH) lleva a cabo una recopilación de los trabajos anteriores y sitúa esta ceca en Celtiberia basándose en la similitud tipológica y epigráfica con otros talleres, punto que comentaremos más adelante; Sánchez Abal, J. L. y García Jiménez, S.; La ceca de Tanusia, Actas 1 Congreso Peninsular de Historia Antigua. Santiago de Compostela, 1988, vol. 2, pp. 149-190 defienden la localización de esta ciudad en Extremadura apoyándose en los hallazgos. En contra L. Villaronga: El hallazgo de monedas, El caso de Tanusia, Gaceta Numismática 97-98, 1990, pp. 79-85 que mantiene la situación septentrional.

2 Untermann, MLH p. 318; Villaronga, L., Numismática Antigua de Hispania, Barcelona, 1979, pp. 194-195 (cit. en adelante como NAH); id., Corpvs Nummvs Hispaniae ante Avgvst aetatem, Madrid, 1994, pp. 230-247 (cit, en adelante como $\mathrm{CNH}$ ).
} 
que circunda el castro (Tamuja). A pesar de estos datos, y juzgando el hallazgo como accidental, L. Villaronga sigue hoy defendiendo la localización de la ceca en Celtiberia citerior ${ }^{3}$; de ahi la importancia de un nuevo lote numismático inédito, procedente de nuevo del castro de Villasviejas del Tamuja, que analizamos a continuación, en el contexto de la circulación monetaria de la región extremeña, lote que parece apoyar la hipótesis de la localización de este taller en el castro cacereño o en sus cercanías.

Dada la escasez de numerario tamusiense, la procedencia de las piezas resulta ser significativamente importante y por ello vamos a centrarnos en un primer momento en la cuestión de los hallazgos. Si tenemos en cuenta que este taller estuvo situado en una región en la que prácticamente no hubo otros en funcionamiento durante estas fechas, resulta razonable esperar que estas monedas alcancen un alto porcentaje de representación en los hallazgos. Es claro que la difusión de la ceca de tamíśia se centra de forma casi exclusiva en el actual territorio cacereño; más aún, de un total de 40 localidades extremeñas en que hemos constatado monedas hispanas sólo 10 han proporcionado numerario de tamiusia (fig. 1). Es importante destacar que en la vecina provincia de Badajoz no ha aparecido ninguna pieza de esta ceca. Los hallazgos se localizan, como vemos, todos en un área compacta y reducida al castro de Villasviejas del Tamuja (Botija-Plasenzuela, Cáceres) donde, no sólo la proporción, sino también la cantidad es elevada dado que el territorio extremeño parece no haber tenido una gran producción propia de moneda ${ }^{4}$.

Veamos ahora otros tipos de argumentación: epigráficos, tipológicos y estilísticos. Desde el punto de vista epigráfico se ha señalado siempre que la leyenda de estas monedas presenta caracteres ple-

\footnotetext{
Villaronga, L., cit, n. I.

Para los talleres monetales extremeños cf. García-Bellido. M. P.: Célticos y púnicos en la Beturia según los documentos monetales, Cuadernos Emeritenses 9, Mérida, 1995, pp. 255-292, agradezco a la $\mathrm{A}$. la cesión de manuscrito antes de su publicación. Ead.: Sobre las dos supuestas ciudades de la Betica llamadas Arsa. Testimonios púnicos en la Baeturia túrdula, Anas 4-5, 1993, pp. 81-92); Balleia (provincia de Badajoz,?) $c f$. ead: Las cecas libiofenicias, VII Jornadas de Arqueologia Fenicio-Pionica, Ibiza, 1993, p. 117); Brutobriga (Villanueva de la Serena?, Badajoz), Galsterer, H., Undersuchungen rum romischen Stadtewesen aut der iberischen Halbinsel. Berlín, 1971, p. 15; Turirecina (Casas de la Reina, Llerena, Badajoz) cf. Garcia-Bellido, M. P.: Las cecas libiofenicias, pp. 114-116. En la ceca de tamiuśia sólo se ha constatado la existencia de una serie que no presenta variacionies importantes; (V 38,1) y Sánchez Abal, J. L. y Garcia Jiménez, S., cit. (n. 1). Sobre la circulación de la zona C. Blázquez, La circulación monetaria en torno a la Via de la Plata desde sus inicios hasta fines del reinado de Commodo, tesis doctoral inédita, Salamanca, 1993.
}

namente celtibéricos y, por sus «dos delfines» se la buscaba en la Celtiberia citerior, por ello la lectura del epigrafe se hizo como tanuśia. Sánchez Abal y Garcia Jiménez tuvieron dificultades para justificar el paso del fonema $\mathrm{n}$ a $\mathrm{m}$ en tanusia $=$ Tamuja ${ }^{5}$. La reciente localización de la ceca en Extremadura permite, según Garcia-Bellido, elegir el sonido $\mathrm{m}$ para la nasal como es frecuente en la Celtiberia ulterior, descartando la n que seria la propia de la citerior. La nueva lectura tamiusia hace la etimologia del topónimo todavia más clara y, permite considerar las series celtibéricas como preámbulo de la latina con el étnico TAMVSIENS, ésta si localizada en la «Andalucia occidental o Extremadura» desde siempre .

Respecto al argumento tipológico, que ha sido trascendente para su tradicional localización en Celtiberia citerior, ya A. Delgado insistía en que su tipo y estilo permitia compararlas con las de sekaisa y śamala aunque había visto ejemplares de esta ceca en varias colecciones ignorando su procedencia ${ }^{?}$. Posteriormente J. Untermann se conforma con señalar que la imagen de estas monedas apunta a Celtiberia citerior, pero sin decidirse entre la zona establecida al norte del río Jalón o bien la de los valles del Jalón y el Henares, y desde el punto de vista estilistico destacaba su semejanza con śekotias, śekaiśa, okalakom, roturkom y samala ${ }^{8}$.

Al examinar detalladamente los tipos y estilos utilizados por estos talleres hemos podido comprobar que, como decía L. Villaronga, «las monedas de tamúsía imitan exactamente las monedas con dos delfines de śekaisa" argumento en el que se basa precisamente el autor para mantener la idea de que debe integrarse en el llamado "grupo de los dos delfines", cuya situación geográfica habria que buscar entre el Jalón y el alto Ebro ${ }^{9}$. La ciudad de śekaisa acuña abundantes series, no sólo en bronce sino también en plata ${ }^{10}$, desde comienzos del siglo $\|$ a.C. pero en Extremadura se encuentran sobre todo y en abundancia las monedas de la última serie (V 65,67,11 y 13), aquéllas cuya semejanza con los bron-

\footnotetext{
S Garcia-Bellido, M. P. cit. n. 4.

- Cf. n. 4 .

7 Delgado, A., Nuevo método de clasificación de las Medallas autónomas de España. t. 3, Sevilla, 1876, pp. 112; a pesar de ello sitúa la ceca en tierras valencianas.

* Untermann, J., MLH, p. 318.

"Villaronga. L., NAH, p. 195; id., cit. (n. 1).

10 Vives, A., La moneda hispánica, Madrid, 1926, vol. 2, pp. 156-160 y láms. 64-65; Villaronga, L., NAH, pp. 133, 178-179, 194 y 196; Dominguez, A.: Ensayo de ordenación del monetario de la ceca de Sekaisa, La Moneda Aragonesa, 1982, pp. 24 ss; Ostalé, M.: Numismática en la Celtiberia. Aportaciones a la ordenación de las acuñaciones de Sekaisa, Gaceta Numismática $86-87,1987$, pp. 121-137.
} 
ces de tamiusia es grande: una gran cabeza masculina que ocupa casi todo el campo, nariz recta, labios gruesos y paralelos, mentón saliente, ojos grandes y convencionales y el cabello con el mismo tipo de rizos, como en los reversos donde los jinetes empuñan una lanza con la mano derecha y con la izquierda llevan las riendas, visten un faldellin plisado y llevan casco con cimera ${ }^{11}$. Hasta el momento estas semejanzas se han tratado de justificar, como hemos visto, en relación con la proximidad geográfica de ambas ciudades; sin embargo, los razonamientos arqueológicos nos llevan la ceca de tamísía a Extremadura y, además, hemos podido comprobar que la circulación de la última serie de las monedas de śekaisa en Extremadura es muy fluida (figs. 1 y 2), logación con el topónimo Tamuja. Dadas las dos áreas paleográficas celtibéricas, nuestro topónimo pertenecería a la occidental, a la Celtiberia ulterior, cuyo mejor paralelo está precisamente en las emisiones de Clunia, kolounioku (V 37,1), la ceca celtibérica más occidental ${ }^{12}$. La complicada argumentación etimológica de Sánchez Abal y Garcia Jiménez hoy resulta innecesaria. La lectura correcta del topónimo ha permitido a García-Bellido defender, por un lado, la procedencia occidental, posiblemente arévaca, de estas gentes dentro de la Celtiberia, por otro, que las monedas con esta leyenda fueran acuñadas por la misma ciudad que posteriormente acuñó piezas con la leyenda TAMVSIENS (V 118, $1-2)^{13}$ y que se trate de celtíberos en territorio vetón.

\begin{tabular}{|c|c|c|c|}
\hline Hallazgos & tamiuśia & sekaisa & Referencias \\
\hline 1. Capote BA & & 1 & Gaceta Num. 97-98. 1990, pp. 66-77 \\
\hline 2. Nertobriga BA & & 1 & Ibidem. p. 72 \\
\hline 3. Hornachuelos BA & & 16 & Jimènez Ávila, 1990, pp. $46-49$ \\
\hline 4. Gab. San Antón BA & & 1 & Gómez Villafranca, 1910 \\
\hline 5. M. de Mérida BA & & 2 & Inéditos \\
\hline 6. Ruecas BA & & 1 & Inédito \\
\hline 7. Cogolludo BA & & 1 & Inédito \\
\hline 8. Trujillo CC & 1 & & I CPHA, 1988, vol. 2, p. 157 \\
\hline 9. Sansueña $\mathrm{CC}$ & 1 & 1 & Gaceta Nüm. 94-95, 1989, p. 140 \\
\hline 10. La Burra CC & 3 & & ICPHA, 1988, vol. 2, p 157 \\
\hline 11. M. de Cáceres & 14 & 6 & Gaceta Núm. $94-95,1989$, p. 140 \\
\hline 12. Cáceres el Viejo CC & 5 & 15 & Olbert. Cáceres el Viejo..., 1984, pp. 257-287 \\
\hline 13. El Castillejo CC & 3 & 2 & Gaceta Núm. $94-95,1989$, p. 140 \\
\hline 14. Castillejo de la Orden CC & 1 & & Gerion2, 1984, pp. $265-323$ \\
\hline 15. V. del Tamuja CC & 101 & 33 & I CPHA, 1988, vol. 2, p. 157 \\
\hline 16. Castillo del Puerto CC & 1 & & Extremadura Arqueológica II, p. 429 \\
\hline 17. El Berrocalillo CC & 1 & & I CPHA, 1988, vol. 2, p. 157 \\
\hline
\end{tabular}

Figura 1.-Hallazgos de monedas de tamiusia y sekaisa en Extremadura.

como comentaremos más abajo, aunque ello es, sin duda, de difícil justificación.

En tercer lugar vamos a centrarnos en el epigrafe de estas monedas puesto que es de gran importancia: ya Untermann, señala la posibilidad de leer esta inscripción con el sonido m o n, pero la supuesta localización en el Jalón le llevaba a elegir la nasal n; sin embargo, es Garcia-Bellido quien defiende la lectura tamiusia basándose en su continuidad en las series latinas de TAMVSIENS y en su homo-

"Consideraciones similares, concretamente paralelos entre sekobirikes y turiasu han sido utilizadas por M. P. GarcíaBellido para apoyar la localización de sekobirikes en la meseta norte (Tesorillo salmantino de denarios ibéricos, Zephyrus 25, 1974, pp. 385-387 y Sobre la localización de SEGOBRIX y las monedas del yacimiento de Clunia, AEspA 67, 1994, pp. 245259).

\section{CIRCULACIÓN MONETARIA \\ EN VILLASVIEJAS DEL TAMUJA CON LOS NUEVOS DATOS}

Este castro prerromano se viene incluyendo dentro del territorio vetón a pesar de que su localización es un tanto marginal dentro del mismo; su emplazamiento es excepcional, tanto desde el punto de vista económico como del estratégico, ya que está situado a medio camino entre el Guadiana y el Tajo, muy próximo a las vías terrestres que comunicaban Andalucía con la Meseta y está ubicado en una impor-

12 Untermann, MLH p. 318; M. P. Garcia-Bellido, Célticos... cit. n. $4 ;$ J. de Hoz: The Celts of the Iberian Peninsula, Zeitschrift fur Celrische Philologie, 45, 1992, pp. 1-37.

13 Garcia-Bellido, M. P., cit. n. 4. 
tante zona minera, ya explotada desde época preromana ${ }^{14}$. Todos estos condicionamientos confieren al yacimiento una serie de peculiaridades que por un lado le vinculan con el munḑo turdetano y por otro con el meseteño. Hasta el momento se ha constatado la existencia de un poblado y dos necrópolis, "El Mercadillo» y «Romazal»; mientras en el poblado, debido al escaso terreno excavado y a la ausencia de estratigrafia, no es posible precisar una secuencia cultural clara, si lo es en la necrópolis. $\mathrm{La}$ presencia de escritura y el abundante material cerámico y numismático denotan un elevado desarrollo cultural que no se observa en otros asentamientos vetones ${ }^{15}$. Por otra parte, no contamos con estudios comparativos dentro de la región extremeña.

Respecto a la cronología del yacimiento se pueden diferenciar dos periodos: el primero se inicia en el siglo iv prolongándose hasta el siglo II a.C. y el segundo abarca desde mediados del siglo II hasta la primera mitad del siglo I a.C. El siglo III a.C. aparece como el momento en que se alcanzó el máximo desarrollo. La cultura material remite por un lado a modelos meridionales y por otro al horizonte cultural meseteño: asi, los ajuares funerarios de «El Mercadillo" consisten en pequeños vasos cerámicos comparables a los de los yacimientos ibero-turdetanos, fusayolas, fibulas, cuentas de collar y algunas piezas aisladas de armamento, mientras que en los de «El Romazal» están presentes nuevos elementos como arreos de caballo, armas, fibulas de La Téne, etc. que constatan una ruptura con la necrópolis anterior y tienen una fuerte vinculación con la Meseta norte ${ }^{16}$. En el mismo sentido apunta el conjunto numismático que presentamos ya que permite aislar con toda nitidez dos fuentes de aprovisionamiento: por un lado, tamiuśia y cecas de la Celtiberia citerior, como titiakoś y śekaisa, y por otro los talleres meridionales, especialmente Cástulo seguido de Obulco. Todos estos datos permiten plantear a F. Hernández la posibilidad de que en el siglo II a.C. se produjeran traslados de población, de forma voluntaria o forzosa, dando lugar a un enclave celtibérico

\footnotetext{
14 Hernández Hernández, F., Rodríguez López, M.D. y Sánchez Sánchez, M. A., Excavaciones en el Castro de Villasviejas del Tamuja (Botija, Cáceres), Mérida, 1989; Hernández Hernández, F.: El yacimiento de Villasviejas y el proceso de romanización, El proceso histórico de la Lusitania oriental en época prerromana y romana, Mérida, 1993, pp. 115-144.

13 Contamos con testimonios epigráficos de época prerromana (Hernández, F.: Nuevos grafitos en Extremadura, NAH 20, 1985, pp. 219-224) a los que hay que sumar el hallazgo reciente, aún no publicado de una tessera hospitalis (García-Bellido. M. P., cit. n. 4).

16 Hernández Hernández, F.: Las necrópolis del poblado de Villasviejas (Cáceres), Extremadura Arqueológica II, MćridaCáceres, 1991, pp. 255-267.
}

dentro del territorio vetón. Sobre este punto volveremos más adelante.

La presencia romana en este yacimiento no parece haber afectado a las estructuras de hábitat ni a los modos de vida, ya que probablemente se trató de una ocupación ocasional a manera de castrum. Este hecho tiene su reflejo en el numerario circulante: la moneda de plata no existe a no ser la procedente de la ceca de Roma con representatividad escasa y el grueso de ella se fecha a fines del siglo II y comienzos del siglo i a.C., concretamente en el 73 a.C., fecha del final de las guerras sertorianas, dato éste del mayor interés para el posible final del habitat.

Vamos a detenernos ahora en la documentación numismática: a pesar de que las monedas recogidas durante la excavación son escasas, contamos con un significativo lote numismático disperso en diferentes colecciones privadas. Algunas de estas piezas han sido publicadas, pero en la mayor parte de los casos no se han especificado los datos concretos referentes a cada una de ellas.

Además, he tenido la oportunidad de estudiar un conjunto de monedas, inédito, que nos ha sido facilitado generosamente por Miguel G. de Figuerola, quien lo recogió en 1984 entre diversos coleccionistas particulares del municipio de Botija ${ }^{17}$. Aunque en un primer momento me planteé la posibilidad de que estos ejemplares fueran los mismos publicados por Sánchez Abal he comprobado que las cecas representadas no son las mismas en ambos lotes y en los casos en que los talleres coinciden las cantidades son diferentes; por ello, siempre que ha sido posible he descartado algunos ejemplares que pudieran ser los mismos, y puesto que contamos con datos más exactos e incluso fotografias he creído conveniente hacer una publicación detallada de este material pues, además de incidir en la abundancia de moneda de tamuśía en la zona, es la primera ocasión en que se puede fechar ésta gracias a la presencia de denarios romano-republicanos.

\section{Lote I. Monedas procedentes de excavación ${ }^{1 \times}$}

En la reciente memoria de excavaciones sólo aparecen fotografiadas 4 monedas, aunque se mencionan otros hallazgos de uases ibéricos que proceden de distintas cecas de la Peninsula Ibérica», pero sin más aclaraciones:

\section{Moneda romano-republicana:}

sm de Roma, anónimo; post. 211 a.C.; $3,50 \mathrm{gr} . ;$ RRC 56/3.

\footnotetext{
17 Reciba desde aqui nuestro agradecimiento por habernos cedido la publicación de este material.

${ }_{18}$ Hernández, F., Rodriguez, M. D. y Sánchez, M. A., cit. (n.
} 14), pp. $105-106$ y 132. 


\section{Monedas hispanas}

as de tamuśia; tránsito ss. II-1 a.C.?;-; V 38,1

2 ases de titiakos; tránsito ss. 11-1 a.C.; 8,66 y 6,82 gr.: V 57,11 .

Lote II Procedentes de este yacimiento

$y$ en distintas colecciones privadas

$\mathrm{Ha}$ sido publicado el siguiente conjunto monetario ${ }^{10}$.

Monedas hispanas

4 ases de airkoiratas; segunda mitad s. II a.C.: 9,90, 7,40, -y-gr.; 25, 21, - y-mm.; V 41.5.

as de arsaos; segunda mitad s. I1-comienzos s. I a.C.; 13,80 gr.; $25 \mathrm{~mm}$; $\vee 47,7$.

4 ases de bilbilis ; segunda mitad s. I1-comienzos s. 1 a.C.:;-: V 63,9

3 ases de bolskan: último cuarto s. II-primer cuarto s. a.C.; 6,70 , -y - gr.: $21,-y-m m . ; ~ V 43,3$.

2 ases de karbika: s. II a.C. : 9 y 7 gr.; 23 y $22 \mathrm{~mm}$.; V 39,11 .

8 ases de kelse; tránsito ss. $11-1$ a.C.: $12,20,8,50, \ldots, \ldots$ y gr.; $29,28,-\ldots,-$ y - mm. : V $61,7$.

semis de ekualakos; tránsito ss. $11-1$ a.C. ?; 6 gr.; $19 \mathrm{~mm}$.: V 55,6.

as de oŕośis; tránsito ss. $11-1$ a.C.; 8,75 gr.; 24 mm.; V 49,1. 3 ases de saltuie; fines s. I a.C.; $11,35,10,30$ y $9,80 \mathrm{gr}$.: 24, 24 y $24 \mathrm{~mm}$.; $\vee 30.1$.

33 ases de sekaiśa; tránsito ss. II-1 a.C.; V 65,13.

101 ases de tamiusia: ¿tránsito ss. I1-1 a.C.?: V 38,1.

21 ases de titiakos; tránsito ss. $11-1$ a.C.; V 57,10.

8 ases de titiakos; tránsito ss. $11-1$ a.C.; V 57,3.

2 ases de turiasu; tránsito ss. 11-1 a.C.; 16,20 y - gr.; 27 y $\mathrm{mm}$.; V 52,4 .

\section{Lote III Conjunto inédito (figs. 7 a 10)}

as de kastilo; c. 195-179 a.C.: 29,70 gr.; $32 \mathrm{~mm}$.; V 68,11. semis de kastilo; c. 195-179 a.C.; 13.10 gr.; 23 mm.; V 68.9 en anv. $\mathrm{cm}$. $X(\mathrm{G} / 19)$.

semis de kassilo; c. 195-179 a.C.: 18,70 gr.; $28 \mathrm{~mm}$. V 68,12 .

as de kaśtilo; c. $165-80$ a.C. : $16 \mathrm{gr.;} 19 \mathrm{~mm}$.; V 70,8-9. semis de Castulo; primera mitad s. । a.C.; 9 gr.; $21 \mathrm{~mm}$.; V 71,2 .

52 aes de kastillo-Castulo?: V?

as de ilturir: siglo ॥ a.C.; $14,50 \mathrm{gr}$ : $26 \mathrm{~mm}$.; V 72,1-3. semis de Malaca: c. 100-45 a.C.; 8 gr.; 22 mm.: V 85, 10. 3 aes de Malaca; $V$ ?

cuadrante de Corduba; comienzos s. 1 a.C.; $6,20 \mathrm{gr}$; 20 mm.; V 118,1 .

20 cuadrantes de Corduba; comienzos s. I a.C.; V 118,? as de Obulco; comienzos s. II a.C.; $30,50 \mathrm{gr}$.; $31 \mathrm{~mm}$.; V 96,1 .

as de Obulco; segunda mitad s. II a.C.; $25 \mathrm{gr}$; $29 \mathrm{~mm}$.; V 96,5 .

3 ases de Obulco; V?

semis de Obulco; s. 1 a.C.; $19,30 \mathrm{gr} . ; 26 \mathrm{~mm}$.; V 97,3.

5 semises de Obulco; V?

semis de Carteia; 90 a.C.; 10 gr.; 23 mm.; V 127.5.

2 semis de Carteia; V?

as de Urso; primera mitad s. I a.C.; 15,80 gr.; $25 \mathrm{~mm}$.; V 112,3 .

as de Urso; primera mitad s. 11 a.C.; V I12,?

as de Carbula; comienzos s. It a.C.; $8,70 \mathrm{gr} . ; 27 \mathrm{~mm}$.; V 113,4 .

2 ases de Carbula; tránsito ss. III-11 a.C.?; V 113,?

as de Ilipense; mediados s. II a.C.; $17 \mathrm{gr} . ; 30 \mathrm{~mm}$; V 107,2.

\begin{tabular}{|cccccccc|}
\hline $\mathbf{N}^{\bullet}$ & Valor & Peso & Módulo & Eje & Ceca & Cronología & Ref. \\
\hline $1^{*}$ & Ae & 15,71 & 25 & 5 & Cerdeña & $264-241$ a.C. & SNG. Copenhagen $\mathrm{n}^{\circ} 192-201$ \\
\hline
\end{tabular}

Monedas romano-republicanas

\begin{tabular}{|ccrcrllrr|}
\hline$N^{*}$ & Valor & Peso & Módulo & Eje & Magistrado & Ceca & Cronologia & RRC \\
\hline $2^{*}$ & Vict. & 1,21 & 14 & 7 & anónimo & Roma? & $215-170$ a.C. & $44 / 1$ \\
$3^{*}$ & As & 27,59 & 31 & 10 & $?$ & $?$ & $211-158$ a.C. & $?$ \\
$4^{*}$ & D & 3,77 & 17 & 5 & M. CARBO & Roma & 122 a.C. & $276 / 1$ \\
$5^{*}$ & D & 3,72 & 18 & 2 & M. CARBO & Roma & 122 a.C. & $276 / 1$ \\
$6^{*}$ & D & 3,37 & 21 & 2 & CN. DOMIT. & Roma & 1166115 a.C. & $285 / 1$ \\
$7^{*}$ & D & 3,74 & 18 & 5 & M.AEMIL.LEP. & Roma & 1146 6 113 a.C. & $291 / 1$ \\
$8^{*}$ & D & 2,64 & 18 & 1 & M.LVCILI RVF. & Roma & 101 a.C. & $324 / 1$ \\
$9^{*}$ & Q & 1,87 & 13 & 7 & Q. TITI & Roma & 90 a.C. & $341 / 3$ \\
$10^{*}$ & Q & 1,37 & 12 & 5 & M. CATO & Roma & 89 a.C. & $343 / 2 b$ \\
$11^{*}$ & Q & 1,53 & 13 & 10 & L.DOSSENVS & Roma & 87 a.C. & $348 / 4$ \\
$12^{*}$ & D & 3,49 & 17 & 10 & L. CASSI Q.F. & Roma & 78 a.C. & $386 / 1$ \\
$13^{*}$ & D & 3 & 17 & 9 & C. MAXSVMVS & Roma & 75 a.C. & $391 / 3$ \\
14 & D & 2,62 & 18 & $?$ & ? & $?$ & $?$ & $?$ \\
\hline
\end{tabular}

19 Sánchez Abal, J. L. y Garcia Jiménez, S.: La ceca de Tanusia, Actas I Congreso Peninsular de $H^{*}$ Antigua, Santiago de Compostela, 1988, pp. 153 y 158; Sánchez Abal, J. L. y Esteban Ortega, J.: Monedas de cecas andaluzas procedentes de Tanusia, Actas del Congreso Internacional «El Estrecho de Gibraltar», Ceuta, 1987, t. I, Madrid, 1988, pp. 1017-103I; García Jiménez, S.: Las monedas del jinete ibérico aparecidas en la provincia de Cáceres, Gaceta Numismática 94-95, fasc. III-IV, 1989, pp. 139-142. 
Monedas hispanas

\begin{tabular}{|c|c|c|c|c|c|c|c|}
\hline $\mathrm{N}^{0}$ & Valor & Peso & Módulo & Eje & Ceca & Cronologia & Vives \\
\hline $15^{*}$ & Sm & 5.93 & 20 & 1 & ekualakoś & Tránsito ss. $\|-1$ a.C.? & 55,5 \\
\hline $16^{\circ}$ & As & 7.08 & 23 & 8 & kaŕbika & s. II a.C. & 39,3 \\
\hline $17^{\circ}$ & As & 9,78 & 23 & 11 & salnuie & Fines s. " a.C. & 30,2 \\
\hline $18^{*}$ & As & 8.21 & 22 & 3 & sékaisa & Tránsito ss. $\|-1$ a.C. & 65.6 \\
\hline $19^{\circ}$ & As & 10,15 & 22 & 5 & sekaisa & Tránsito ss. $11-1$ a.C. & 65,11 \\
\hline $20^{*}$ & As & 9,49 & 21 & 10 & Sekaisa & Tránsito ss. $\|-1$ a.C. & 65,11 \\
\hline $21^{*}$ & As & 9,19 & 23 & 5 & Sekaisa & Tránsito ss. $\| 1-1$ a.C. & 65.11 \\
\hline $22^{*}$ & As & 8,14 & 23 & 7 & sekaisa & Tránsito ss. $11-1$ a.C. & 65,11 \\
\hline $23^{*}$ & As & 8,12 & 23 & 7 & sekuisa & Tránsito ss. $\|-1$ a.C. & 65,11 \\
\hline $24^{*}$ & As & 7,47 & 23 & 1 & sekaisa & Tránsito ss. $\|-1$ a.C. & 65,11 \\
\hline $25^{*}$ & As & 7,30 & 21 & 10 & sekaisa & Tránsito ss. II-1 a.C. & 65,11 \\
\hline $26^{*}$ & As & 6,35 & 21 & 5 & sekaisa & Tránsito ss. $\|-1$ a.C. & 65,11 \\
\hline $27^{*}$ & As & 5,43 & 21 & ? & sekaisa & Tránsito ss. $\| 1-1$ a.C. & 65,11 ? \\
\hline $28^{*}$ & As & 10,45 & 24 & 3 & taniuśia & Tránsito ss. $\|-1$ a.C. & 38,1 \\
\hline $29^{*}$ & As & 9,63 & 24 & 1 & taniusia & Tránsito ss. \|l- a.C.? & 38,1 \\
\hline $30^{*}$ & As & 8,83 & 22 & 4 & tamiuśia & Tránsito ss. $\|-1$ a.C.? & 38,1 \\
\hline $31^{*}$ & As & 8,72 & 22 & 3 & tamiusia & Tránsito ss. $\|-1$ a.C.? & 38.1 \\
\hline $32^{*}$ & As & 7 & 23 & 3 & tamiuśia & Tránsito ss. $\| 1-1$ a.C.? & 38.1 \\
\hline $33^{*}$ & As & 6,91 & 22 & 1 & tamiuśia & Tránsito ss. $\| 1-1$ a.C.? & 38.1 \\
\hline $34^{*}$ & As & 6,80 & 21 & 1 & tamiuśia & Tränsito ss. $\| t-1$ a.C.? & 38,1 \\
\hline $35^{*}$ & As & 5,10 & 21 & 12 & tamiusia & Tránsito ss. $\|-1$ a.C.? & 38,1 \\
\hline $36^{*}$ & As & 9,48 & 23 & 10 & titiakoś & Tránsito ss. $\|-1$ a.C. & 57,10 \\
\hline $37^{*}$ & As & 8.67 & 23 & 12 & titiakos & Tránsito ss. $\|-1$ a.C. & 57.4 \\
\hline $38^{*}$ & As & 8,43 & 24 & 11 & titiakos & Tränsito ss. $\|-1$ a.C. & 57,1 \\
\hline $39^{*}$ & As & 7.89 & 22 & 11 & titiakos & Tránsito ss. II-ı a.C. & 57.3 \\
\hline $40^{*}$ & As & 7,33 & 23 & 1 & titiakos & Tránsito ss. $\|-1$ a.C. & 57.11 \\
\hline $41^{*}$ & As & 7.26 & 22 & 2 & titiakos & Tránsito ss. $\|-1$ a.C. & 57,11 ? \\
\hline $42^{*}$ & $\mathrm{As}^{2 a}$ & 3,73 & 24 & 12 & hispana & ? & ? \\
\hline $43^{*}$ & As & 18,15 & 26 & 9 & kaśtilo & c. $179-150$ a.C. & 69,3 \\
\hline $44^{*}$ & As & 17.42 & 26 & 2 & kaśtilo & c. $165-80$ a.C. & 70.9 \\
\hline $45^{*}$ & As & 12.87 & 24 & 1 & kaśtilo & c. $165-80$ a.C. & 70,9 \\
\hline $46^{*}$ & As & 12,24 & 27 & 10 & kaśtilo & c. $165-80$ a.C. & 70,9 \\
\hline $47^{*}$ & $\mathrm{Sm}$ & 4.83 & 18 & 9 & kaśtilo & c. $150-80$ a.C. & $70,5 ?$ \\
\hline $48^{*}$ & $\mathrm{Sm}$ & 8,68 & 23 & 6 & kaśtilo & Primera mitad s, । a.C. & 71,6 ? \\
\hline $49^{*}$ & As & 15,03 & 26 & 4 & Obulco & Comienzos s. 11 a.C. & 95,6 \\
\hline $50^{*}$ & As & 12,37 & 25 & 3 & Obulco & Comienzos s. $\|$ a.C. & 95,6 \\
\hline $51^{*}$ & $\mathrm{Sm}$ & 3,58 & 20 & $?$ & Obulco & s.। a.C. & $173.3 ?$ \\
\hline $52^{*}$ & $\mathrm{Sm}$ & 2,44 & 16 & 5 & Obulco & S. 1 a.C. & $98,1 ?$ \\
\hline $53^{*}$ & $\mathrm{Sm}$ & 2,18 & 15 & $?$ & Obulco ó kaśtilo & ? & $?$ \\
\hline $54^{*}$ & $\mathrm{Sm}$ & 1,98 & 13 & 11 & Obulco ó kaśtilo & ? & ? \\
\hline $55^{*}$ & Sm & 1,62 & 13 & $?$ & Obulco ó kaśtilo & ? & ? \\
\hline $56^{*}$ & $\mathrm{Sm}$ & 1,61 & 14 & ? & Obulco ó kaśtilo & $?$ & $?$ \\
\hline $57^{*}$ & As & 10,20 & 26 & 3 & Brutobriga & s. । a.C. & 118,1 \\
\hline $58^{*}$ & $\mathrm{Sm}$ & 6,55 & 22 & 4 & Carteia & 101 a.C. & 126,8 \\
\hline $59^{*}$ & Qd & 5,41 & 18 & 1 & Corduba & Comienzos s. I a.C. & 118,1 \\
\hline $60^{*}$ & Qd & 4,18 & 17 & 7 & Corduba & Comienzos s. 1 a.C. & 118,1 \\
\hline $61^{\circ}$ & $\mathrm{Sm}$ & 8,18 & 21 & - & Malaca & c. $110-45$ a.C. & 85,10 \\
\hline 62 & As & - & 23 & 12 & Salacia & Comienzos S. I a.C.? & 84,1 \\
\hline $63^{\circ}$ & As & 14,45 & 28 & 2 & Tamusiens & Segunda mitad s. ॥ a.C. & $118,1 ?$ \\
\hline
\end{tabular}

Como ya hemos señalado supra, este conjunto monetario, hasta ahora inédito, procede en su mayoría de hallazgos de superficie, hoy en colecciones particulares, y sólo cuatro monedas proceden de excavaciones: Contamos con un total de trescientas

${ }^{20}$ Es un alma de bronce de un denario forrado cuya emisión es imposible identificar. once monedas que se distribuyen en los siguientes períodos:

\begin{tabular}{|lrr|}
\hline \multicolumn{1}{|c|}{ Cronología } & Total & \multicolumn{1}{c|}{$\%$} \\
\hline Antes 195 a.C. & 4 & 1,28 \\
195-72 a.C. & 307 & 98,72 \\
\hline Total & 311 & \\
\hline
\end{tabular}




\section{Periodo ante 195 a.C. (fig. 2)}

A pesar del importante papel que desempeña la amonedación en este periodo de guerras la circulación es muy limitada, con sólo el $1,28 \%$ del total del numerario localizado, pero vamos a comentarlo con algún detenimiento puesto que las piezas aparecidas son altamente significativas.

\begin{tabular}{|lcccccc|}
\hline Cecas & Vict. & A & Sm & Ae & Total & $\%$ \\
\hline $\begin{array}{l}\text { Cerdeña } \\
\text { Roma }\end{array}$ & 1 & 1 & 1 & 1 & 1 & 25 \\
\hline Total & 1 & 1 & 1 & 1 & 4 & \\
\hline
\end{tabular}

Figura 2.-Monedas anteriores al 195 a.C. halladas en ViIlasviejas del Tamuja (Botija-Plasenzuela, Cáceres).

La pieza más antigua localizada en este yacimiento es un ae púnico acuñado en Cerdeña entre 264 y 241 a.C. Hemos seguido los desplazamientos de estas monedas fuera de la isla y hemos podido constatar su presencia en el sur de la Galia ${ }^{21}$, en Mónaco ${ }^{22}$, en Ampurias, Ibiza y Menorca ${ }^{23}$, en algún lugar de Andalucia ${ }^{24}$ y en el norte de Africa ${ }^{25}$. Los hallazgos en el litoral mediterráneo puden ser testimonios de las relaciones con el mundo púnico ya que están constatadas las exportaciones e importaciones ${ }^{26}$. Sin embargo, la penetración en el sur de Hispania encaja mejor en el contexto de la Segunda Guerra Púnica.

Respecto a la aparición de un victoriato también conviene hacer algún comentario, puesto que hasta ahora su difusión geográfica parecía restringirse a la costa levantina y Andalucía oriental, exceptuando el hallazgo de Numancia ${ }^{27}$. Pero también se han

21 Thompson, M., Morkholm, O., Kraay, C. M., An Inventary of Greek Coin Hoards, Nueva York, 1973, n. 2355 y 2358.

22 Idem., n. 2354.

${ }^{23}$ Ripollés, P. P., La circulación monetaria en la Tarraconense mediterránea, Valencia, 1982, pp. $175,184,235$ y 243 244.

24 Villaronga, L.: Necesidades financieras de la P. Ibérica durante la II Guerra Púnica y primeros levantamientos de los iberos, Nummus IV-VI, 1981-83, p. 131.

${ }^{25}$ Hallazgos similares han tenido lugar en Túnez y Trípoli, cf. Thompson, M., Morkholm, O, Kraay, C. M., cit. (n. 21), n. 2272,2305 y 2294.

26 No compartimos la opinión de M. Campo (Circulación monetaria en Menorca, ISNB, Barcelona, 1979, p. 97) que piensa que estas piezas debieron ser consideradas objetos exóticos y no un medio de cambio.

27 Para evitar la enumeración de estos hallazgos remitimos a Lechuga Galindo, M., Tesorillos de moneda romano-republicana de la región de Murcia, Murcia, 1986, pp. 74-77 y a GarcíaBellido, M. P., El tesoro de Mogente y su entorno monetal, Valencia, 1990, pp. 107-127. producido hallazgos de victoriatos en la mitad occidental peninsular: en Bornos (Cádiz) ${ }^{2 x}$, en uno de los tesoros de Puebla de los Infantes (Sevilla) ${ }^{29}$, en el poblado de Hornachuelos (Ribera del Fresno, Badajoz) ${ }^{30}$ en el tesoro de Almadenejos (Ciudad Real) ${ }^{31}$ y en Coca (Segovia) ${ }^{32}$. En todos estos casos, al igual que en el de Villasviejas del Tamuja, los victoriatos debieron llegar con posterioridad al 170 a.C., fecha en que dejaron de emitirse ${ }^{33}$.

Lo más probable es que las piezas correspondientes a este primer período sean simplemente una muestra de circulación residual, ya que esta zona no estaba monetizada en aquel momento y se encuentra alejada del área de influencia cartaginesa.

\section{Periodo 195-72 a.c. (figs. 3 y 4)}

Aunque lo deseable seria mantener una periodización más breve en este caso nos tenemos que enfrentar con una serie de cuestiones como, por ejemplo, el hecho de que en algunas ocasiones desconozcamos la serie a la que pertenecen las monedas y no sea posible precisar las fechas de emisión, o bien el hecho de que la cronologia propuesta para estas piezas no encaja en nuestro esquema cronológico. Por ello finalmente nos hemos decidido a analizar conjuntamente el grueso del material numismático que, como puede observarse pertenece al siglo $\|$ y comienzos del siglo I a.C.

El primer aspecto a destacar es que la moneda de plata procede en su totalidad de la ceca de Roma y supone el $3^{\prime} 58 \%$ del total de este periodo. Hay que tener en cuenta que en las cecas meridionales en este momento no se están realizando emisiones en plata. La importancia del conjunto inédito radica en que la plata romana que acompaña a las monedas hispanas nos permite proponer una fecha aproximada para el final del yacimiento: los denarios republicanos del lote inédito marcan como fecha final el año 75 a.C. (denario $\mathrm{n}^{\circ} 13$ ), dato que podría relacionarse con las campañas sertorianas; sin embargo,

${ }^{2 x}$ Bost, J. P., Chaves, F., Depeyrot, G. Hiernard, J. et Richard, J. C., Belo IV. Les Monnaies, Madrid, 1987, p. 25 , n. 19.

${ }^{24}$ Chaves, F.: Tesoros de monedas inéditos ocultados en la Bética durante la República: I. El conjunto de Puebla de los Infantes (Sevilla), Anas 1, 1988, pp. 133-168.

30 Jiménez Avila, F. J., Estudio numismático del poblado de Homachuelos (Ribera del Fresno, Badajoz), Cáceres, 1990. p. 29.

31 Canto García, A.: Sobre un hallazgo de denarios en Almadenejos (Ciudad Real), Oretum 3, 1987, pp. 293-317.

${ }^{32}$ Blanco García, J. F., Moneda y circulación monetaria en Coca (siglo II a.C. $-v$ d.C.), Segovia, 1987, p. 38, n. 1.

33 Sobre la fecha de acuñación del victoriato $c f$. Garcia-Bellido, M. P., cit. (n. 27), pp. 107-127. 


\begin{tabular}{|c|c|c|c|c|c|c|c|c|}
\hline Cecas & D & $\mathbf{Q}$ & $\mathbf{A}$ & Sm & Qd & aes & Total & $\%$ \\
\hline Roma & 8 & 3 & & & & & 11 & 3,58 \\
\hline airkoritas & & & 4 & & & & 4 & 1,30 \\
\hline arsaos & & & 1 & & & & 1 & 0,32 \\
\hline bolikan & & & 3 & & & & 3 & 0,97 \\
\hline titiakoś & & & 31 & & & & 31 & 10,09 \\
\hline turiasu & & & 2 & & & & 2 & 0,64 \\
\hline kelse & & & 8 & & & & 8 & 2,60 \\
\hline bilbilis & & & 4 & & & & 4 & 1,30 \\
\hline karbika & & & 2 & & & & 2 & 0.64 \\
\hline ekualakoś & & & & 1 & & & 1 & 0,32 \\
\hline oivśis & & & 1 & & & & 1 & 0,32 \\
\hline saltuie & & & 3 & & & & 3 & 0,97 \\
\hline śekaisa & & & 33 & & & & 33 & 10,75 \\
\hline tamiusía & & & 102 & & & & 102 & 33,22 \\
\hline kaśtilo & & & 1 & 1 & & 52 & 54 & 17,59 \\
\hline ilturirir & & & 1 & & & & 1 & 0.32 \\
\hline Obulco & & & 5 & 5 & & & 10 & 3,25 \\
\hline Brutobriga & & & 1 & & & & 1 & 0,32 \\
\hline Carbula & & & 3 & & & & 3 & 0,97 \\
\hline Carteia & & & & 3 & & & 3 & 0,97 \\
\hline Corduba & & & & & 21 & & 21 & 6,84 \\
\hline Ilipense & & & 1 & & & & 1 & 0,32 \\
\hline Malaca & & & & 1 & & 3 & 4 & 1,30 \\
\hline Salacia & & & 1 & & & & 1 & 0,32 \\
\hline Tamusiens & & & 1 & & & & 1 & 0,32 \\
\hline Urso & & & 1 & & & & 1 & 0,32 \\
\hline Total & 8 & 3 & 209 & 11 & 21 & 55 & 307 & \\
\hline
\end{tabular}

Figura 3 - Monedas fechadas entre 195 y 72 a.C. halladas en Villasviejas del Tamuja (Botija-Plasenzuela, Cáceres).

Sánchez Abal nos informa, aunque sin más precisiones, de la «aparición de denarios republicanos en el castro que llegan hasta el año 40 a.C. ${ }^{34}$.

Aunque no disponemos de referencias literarias sobre la presencia romana en el castro sí contamos con algunos materiales, como ánforas, cerámica común y paredes finas, que permiten suponer una ocupación transitoria del yacimiento; las ánforas apulas y Dressel 1 así como la cerámica campaniense pueden compararse con las exhumadas en Cáceres el Viejo, sin embargo aquí el momento final de la ocupación , coincidiendo posiblemente con las luchas de César y Pompeyo, parece estar marcado por

34 Sánchez Abal; J. L. y García Jiménez, S., cit. (n. 1), p. 158. Hay que tener en cuenta que nuestro lote de monedas fue recogido en 1984, mientras que el de Sánchez Abal ha sido publicado en 1988 por lo que es posible que hayan aparecido más piezas que cubran ese intervalo de tiempo. la cerámica de paredes finas datada en una fecha republicana $\operatorname{tardí}^{35}$.

Entre las cecas peninsulares la que cuenta con una mayor representación es tamúsia. La importante cantidad, 102 monedas, y el porcentaje, $33,22 \%$, en el que esta ceca entra a formar parte de la circulación monetaria es uno de los más altos registrado hasta el momento en un yacimiento. Como ya hemos constatado supra, el resto de los hallazgos de esta ceca se localiza en un área cercana y muy reducida apoyando la localización del taller en este castro. Respecto al porcentaje hay que destacar que no alcanza el $50 \%$, como era de esperar en las ciudades con ceca propia, pero hay que tener en cuenta que esto depende de la cantidad de emisiones y las de tamiusia son muy escasas. Este podría ser un caso

35 Hernández, F., Rodriguez, M. D. y Sánchez, M. A., cit. (n. 14), pp. 127-128, 137. 


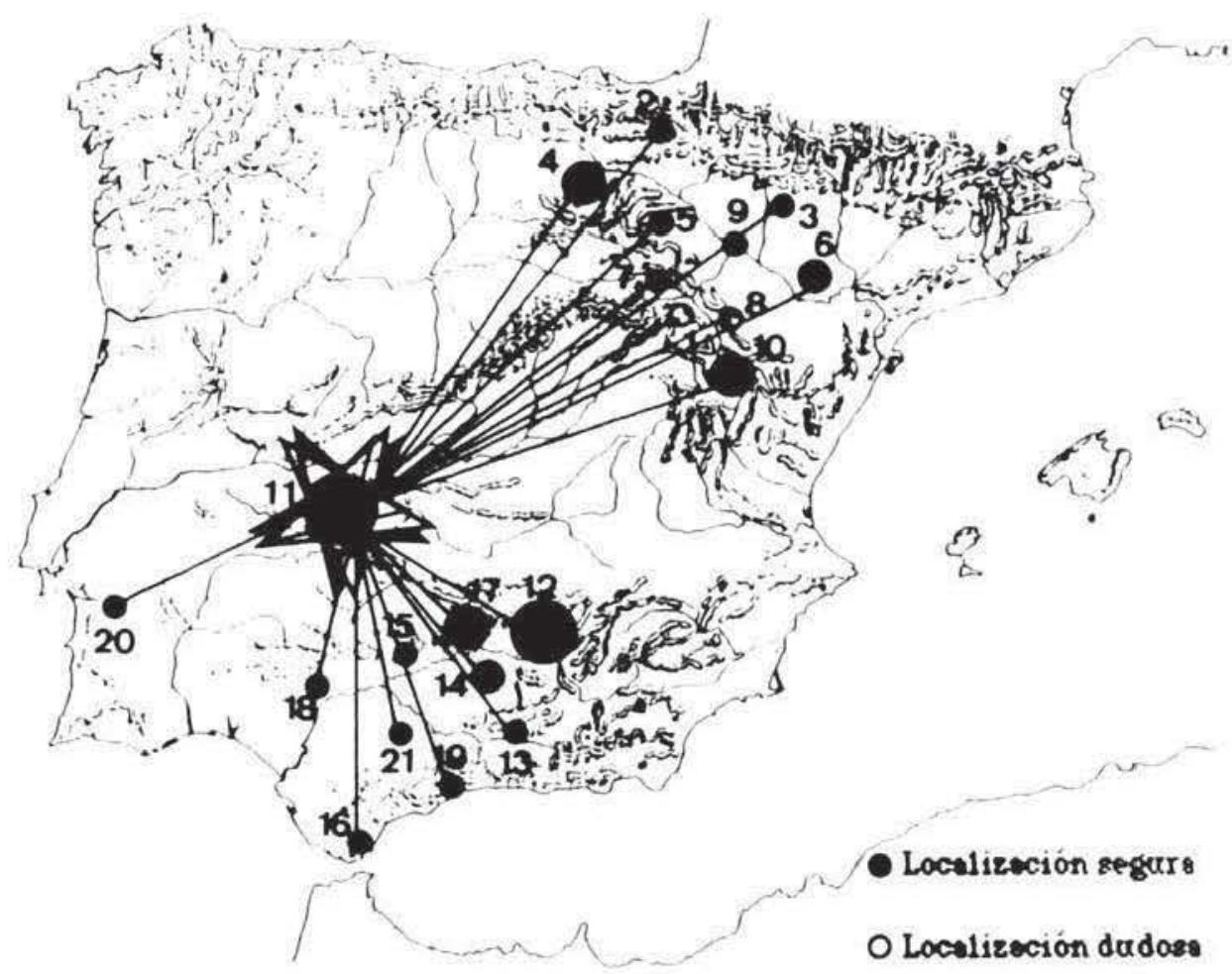

Figurat. Procedencia de las moncdas hispanas halladas en Villastefas del Tamuja (Botija-Plasen/acla, (aceres) I ainekonulas.

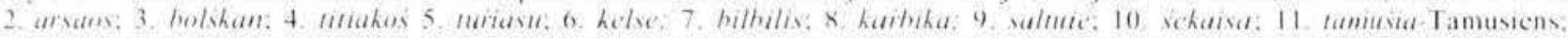
12. hasile. 13. ilmirr: 14. Obulco. 15. Carbula. 16. Carteia. 17. Corduba, I8 Ilipense: 19. Malaca. 20. Salacia. 21. Urso. No localizadas en el mapa ekualakos. omosis y Brutobriga.

similar al de kelin. cuya ceca participa en la masa monetaria de Los Villares (Caudete de las Fuentes. Valencia) con el $35 \%$ o el de kontehakom hel ( $\mathrm{Ca}$ bezo de las Minas, Zaragoza) que representa solo el $29.41^{\circ} \%$ del total ${ }^{\text {* }}$.

El segundo lugar es ocupado por kastilo que aporta el $17.59 \%$ del total del numerario de este periodo: habria sido interesante poder analizar a qué emisiones de esta ceca corresponden las piezas halladas. pero sólo contamos con las referencias de Sanchez Abal. La vecina Obulco representa con ases y semises el $3.25 \%$. Hay que destacar que los semises parecen ser piezas de imitación posiblemente con un carácter similar a los hallados en Riotinto y en el poblado de Hornachuelos (Ribera del Fresno, Badajoz) ${ }^{17}$.

De las acuñaciones del área del Ebro también

\footnotetext{
Ripolles, P. P. cit, (n. 23), Pp. $492-496$

Chaves, F. Hallazgo de monedas en Riotinto (Huelva). //omenaje a A Beltrin, Zaragoza, 1986, pp. 863-872 publica un ocultamiento compuesto por una gema, un troso de plata. un pendiente de oro, un quadrigatus fragmentado (siglo н a. ( $;$ Roma). I denarios forrado de MN. ACILIVS (RR ( 442 1: 49 a. ( : Roma). un cuadrante de Bailo (V 91. 4) y 86 semises de (Castulo (V 71.6 de imitación. Para las piezas de Hornachuelos: Jiméne, Avila. F. J.. cit. (n. 30$)$. pp. 39 y 72 .
}

está representada kelse $(2,60 \%)$ y del resto de las cecas peninsulares son las celtibericas las que juegan un papel más destacado, especialmente sekaisa $(10.75 \%)$. Y a continuación se situan las monedas procedentes del norte y del valle del tibro, entre las que sobresale de forma muy especial la aportacion de titiakos $\left(10,09^{\circ} 0\right)$. Pero quizás lo más significativo sea que la participación de todos estos talleres siempre sea realizada con moneda de bronce.

Los valores más frecuentes son el as, a continuación los cuadrantes y después los semises. Esta abundancia relativamente elevada de divisores parece indicar una alta monetización de la economia del castro. No creemos que sea casual que después de lamiusia. la ceca local, las más representadas pertenezcan a talleres localizados también en ámbitos mineros, ya que es precisamente en estos ámbitos donde se conjugan toda esta serie de caracteristicas $^{3 \times}$.

Durante mucho tiempo el único conjunto numismático significativo extremeño conocido era el pro-

\footnotetext{
ix Garcia-Bellido. M. P. Nuevos documentos sobre mineria y agricultura romanas en Hispania, Af sy A 153-154, 1986, pp 34-38
} 
cedente del campamento de Cáceres el Viejo ${ }^{34}$, conjunto que, dada su composición, se pensó no debía corresponder a una circulación local sino que dichas monedas habrian sido traidas por personas itinerantes procedentes de otros lugares ${ }^{\text {to }}$. Ahora contamos con la posibilidad de examinar de forma conjunta el comportamiento numismático de otros yacimientos extremeños; asi, además de Villasviejas del Tamuja (Botija-Plasenzuela, Cáceres) y Cáceres el Viejo (Cáceres) conocemos las monedas halladas en el Castrejón de Capote (Higuera la Real, Badajoz) y las del poblado de Hornachuelos (Ribera del Fresno, Badajoz) ${ }^{41}$. En todos se observa la existencia de dos fuentes fundamentales de abastecimiento que parecen indicar la existencia de fuertes contactos con el valle del Guadalquivir por un lado y por otro con Celtiberia, dato ya constatado para La Loba (Fuente Obejuna, Córdoba) ${ }^{42}$.

Vamos a detenernos ahora sobre este último punto, puesto que el material numismático que hemos recopilado entre los hallazgos de época republicana en la región extremeña arroja nuevas perspectivas sobre este tema y permite conjugar todos los argumentos antes expuestos. La importancia cuantitativa del grupo celtibérico se debe a una sola ceca: sekaiśa. M. Medrano ${ }^{43}$ ha realizado un estudio sobre la circulación de estas piezas y recoge 30 lugares de hallazgo, todos localizados en la mitad oriental hispana, excepto Cáceres el Viejo (fig. 6); en dicho trabajo señala que cuanto más nos alejamos de la zona de Calatayud se encuentra un menor número de bronces de sékaiśa. El autor opina que el modelo de distribución monetal ha de ponerse directamente en relación con la conquista de Hispania y los movimientos de tropas, factor que ya fué indicado por A. Dominguez ${ }^{44}$, y que explicaria que los hallazgos jalonen las vías de comunicación más importantes, asi como que su mayor concentración se produzca en asentamientos militares y zonas de

\footnotetext{
${ }^{59}$ Beltrán Lloris, M.: Problemas de Arqueologia cacereña: el campamento romano de Cáceres el Viejo (Cáceres). Estudio numismático, Numisma 120-131, 1974, pp. 225-298; Hildebrant. H. J.: Die Münzen aus Cáceres el Viejo, en Ulbert, G., Cáceres el Viejo. Ein spatrepublikanisches Legionslager in SpanischExtremadura, Mainz, 1984, pp. 257-297.

${ }^{40}$ Villaronga, L., Gaceta Numismática 97-98, pp. 82-83.

" C. Capote: Berrocal, L. y Canto, A.: Aproximación al estudio de la numismática prerromana del suroeste peninsular: el ejemplo del castro de Capote, Gaceta Numismática 97-98, 1990. pp. 67-77; Hornachuelos: Jiménez Ávila, F. J. cit. (n. 30).

${ }^{42}$ Garcia-Bellido, M. P., cit. (n. 38) p. 36.

43 Medrano Marqués, M. M.: Estudio de la circulación de las emisiones de Sekaisa mediante la aplicación de un modelo estadistico, Gaceta Numismática 86-87, 1987, pp. 139-160.

44 Domínguez Arranz, A.: Ensayo de ordenación del monetario dela ceca de Sekaisa, La Moneda Aragonesa, Zaragoza, 1982. p. 34.
}

fuerte conflictividad. De este modo se observa de forma muy clara que hay una serie de hallazgos que se han producido a lo largo de un camino que partiendo de sekaisa baja por Teruel (Villahermosa del Campo- Torrecilla del Rebollar-Cella-Alto Chacón) y continúa por el área noroccidental de Valencia (Sinarcas-Camporrobles-Caudete de las Fuentes). La constatación de este camino es sin duda de gran importancia puesto que pone de relieve el hecho de que el tráfico principal de gentes y tropas se produce en esta época entre la Celtiberia y el área levantina, y no a través del valle del Ebro, aunque los hallazgos de Botorrita y Alcañiz demuestran que también se emplearon los caminos paralelos a esta via fluvial. Por otra parte, se ha constatado igualmente la presencia de estas monedas en la ruta principal de acceso a la Meseta norte, que viene dada por los puntos de Arcobriga, Numancia, Osca, Tiermes y Clunia, camino que enlazaria desde Numancia con Logroño y Pamplona. Finalmente los hallazgos señalan también la via de penetración hacia la Meseta Sur que, partiendo de la ceca, continuaria por Luzaga y Uclés hasta conectar con Cáceres. Sin embargo, aunque en el trabajo de Medrano no se recogen más hallazgos de monedas de sekaisia en la mitad occidental que los de Cáceres el Viejo, hemos podido constatar que su difusión fué mucho más amplia y que aparece vinculada con cierta frecuencia a ámbitos mineros (fig. 6) ${ }^{45}$.

Un dato de suma importancia es que la casi totalidad de las monedas de sekaiśa que hemos recopi-

\footnotetext{
4s Hallazgos de monedas de bronce de sekaisa en el territorio occidental peninsular: 2 ases en el Museo de Pontevedra (V 65.6), Garcia Alén, A.: La moneda hispánica en el Museo de Pontevedra, El Museo de Pontevedra 7, 1952, pp. 99-140): 2 ases en EI Castillejo (V 65,13). Garcia Jiménez, S. cit. n. 19, p. 140; 33 ases en Villasviejas del Tamuja, ibidem: en Cáceres el Viejo 8 ases (V 65.6) y 7 ases (V 65,11). Hildebrant, H. J. cit. n. 39, pp. 257-297; en el Museo de Cáceres I as (V 65,6), 2 ases (V 65,7) y 3 ases (V 65,13). Paniagua Berrocal, S.: Monedas del jinete ibérico en el Museo Arqueológico Provincial de Cáceres, Gaceta Numismática 86-87, 1987, pp. 107-120; I as (V 65,13) en Sansueña, Garcia Jiménez, S., cit. supra; 2 ases (V 65,7) en el Museo de Mérida, inéditos; I as (V 65,6) en Ruecas, inédito; I as (V 65,6) en Cogolludo, inédito; en Hornachuelos 1 as (V 65,11), 12 ases (V 65,11), I semis (V 65,12), I as (V65,5) y I as (V 65.6), Jiménez Ávila, F. J., cit. (n. 30), pp. 46-49; 1 as (V?) en Nertobriga, Berrocal, L. y Canto, A. cit. (n. 41) pp. 67-77; 1 as (V 65,11 ) en Capote, ibidem; 9 monedas en el Museo de Evora (Farinha dos Santos, M.: Moedas com inscriçoes púnicas de quatro oficinas hispánicas do litoral pertencentes a coleccao de Museu de Evora, CAN 14, 1975, pp. 795-810); I as en Villanueva del Rio y Minas, Fernández Chicarro, C.: Recientes ingresos numismáticos en el Museo Arqueológico de Sevilla, Estudios de Numismática Romana, Barcelona, 1964, p. 29; 1 as en Cala, Otero Morán, P.: Consideraciones sobre la presencia de acuñaciones celtibéricas en zonas mineras de la Hispania Ulterior, Xlih Int.Num.Cong., Louvain-la-Neuve, 1993, vol. 2, p. 54; 1 as en Sotiel Coronada, ibidiem; 6 ases en La Loba, Garcia-Bellido.
} 


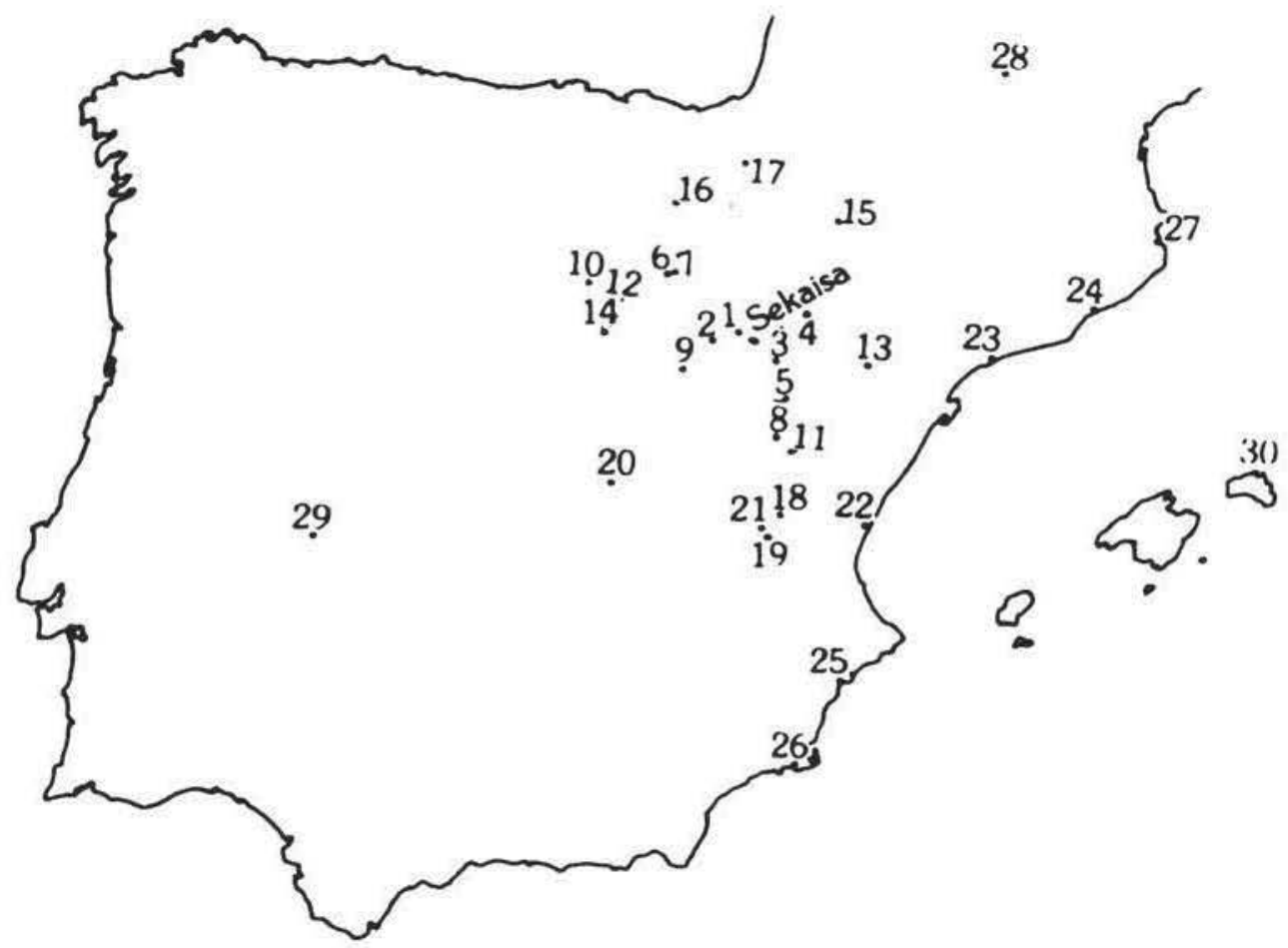

Figura 5.-Hallazgos de monedas de bronce de sekaisa (según M. Medrano, cit. n. 44).

lado entre los hallazgos del occidente peninsular pertenecen a la última serie acuñada por esta ceca, es decir a la que tiene como símbolo en el anverso un delfin delante y otro detrás de la cabeza masculina (V 65, 6, 7, 11 y 13). Ya hemos señalado antes el paralelismo y la similitud existente entre dichas monedas y las acuñadas en tamíúía (V 38,1); sin embargo, hasta el momento, se ha tratado únicamente de justificar esa semejanza en relación con la proximidad geográfica de ambas ciudades. Ahora bien, creemos que el hecho de que las monedas de tamísía nos ofrezcan una epigrafia y una tipología plenamente celtibéricas puede indicarnos la existencia de un contacto intimo entre Celtiberia y la región extremeña datable precisamente en los años de emisión de la última serie de śekaisa, la más abundante en Extremadura y la que copia la ceca de Tamusia.

Todas estas suposiciones nos parecen aún más probables si observamos que, aunque tradicionalmente a la serie de śekaisa de los dos delfines se le

M. P. cit. (n. 38), p. 36; 16 monedas en una colección particular reunida en Córdoba (A. Delgado, cit. (n. 7) vol. 3, p. 375); 2 ases en Diógenes, Domergue, C.: La mine antique de Diógenes (Ciudad Real), MCV 3, 1967, pp. 54 ss; 1 as en La Bienvenida, Arévalo, A. y Canto, A.: Moneda y Arqueologia. El ejemplo de Ciudad Real, Gaceta Numismática 113, 1994, p. 18; 1 as en Alarcos, ibidem pp. 21-22; 1 as en Villanueva de la Fuente, ibidem, p. 23; 1 as en El Centenillo, Otero, P., cit. supra, p. 52. viene atribuyendo una cronología sertoriana, las excavaciones en el Castrejón de Capote (Higuera la Real, Badajoz) han llevado a Berrocal y Canto a retrotraer esa fecha hasta fines del siglo II a.C. ${ }^{46}$. De esta forma resulta posible aceptar que las acuñaciones de tamíusia sean posteriores, es decir, que tuvieran lugar en el primer cuarto del siglo I a.C. tras haber conocido las de śekaisa e imitarlas, estableciéndose así un enlace tipológico entre ambas emisiones. Por último conviene recalcar que en el resto del territorio meseteño no ha aparecido ninguna moneda de tamísíi ni en excavaciones ni en tesoros, a pesar de que conocemos la existencia de numerosos conjuntos numismáticos.

Los hallazgos de monedas de sekaisa en la zona meridional (fig. 6) parecen marcarnos una penetración desde la Meseta siguiendo el camino natural en sentido Este-Oeste que bordeaba el extremo occidental de Sierra Morena y desde allí toma un eje hacia los valles del Tajo y el Guadiana, otro hacia las explotaciones mineras de las provincias de Ciudad Real y Córdoba y un tercero que se dirige a los

46 Berrocal Rangel, L. y Canto Garcia, A. cit. (n. 41), pp. 67. 77; la misma cronología es propuesta por Ostalé, M.: Numismática en la Celtiberia. Aportación a la ordenación de las acuñaciones de Sekaisa, Gaceta Numismática 86-87, 1987, pp. 129 basándose en los hallazgos de Cáceres el Viejo. 


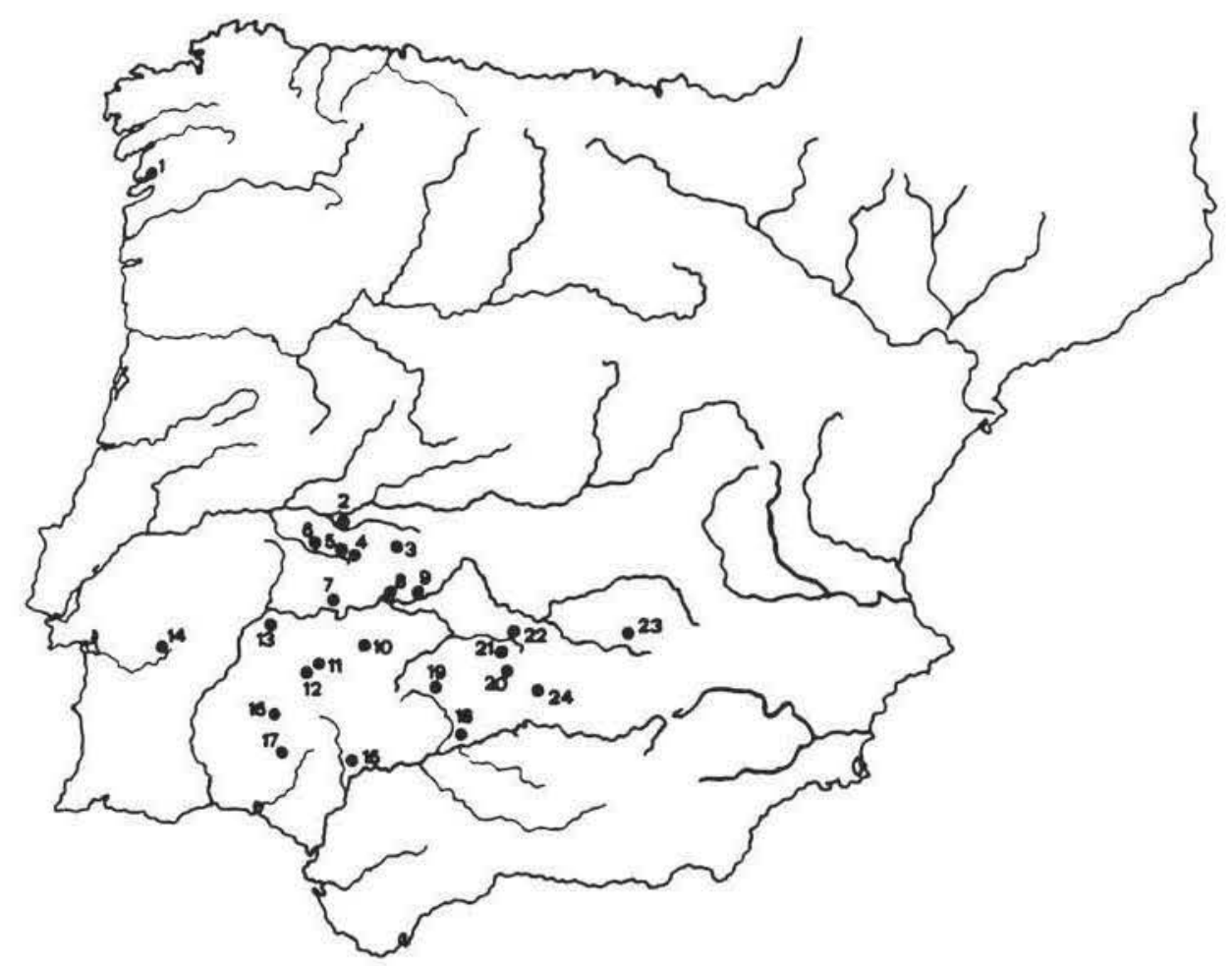

Figura 6.- Hallazgos de monedas de bronce de jekaisa en la zona occidental de la P. Ibérica: 1. Museo de Pontevedra: 2. El Castillejo (Santiago del Campo, CC); 3. Villasviejas del Tamuja (Botija-Plasenzuela, CC); 4. Cáceres el Viejo (CC); 5. Museo de Cáceres; 6. Sansueña (Arroyo de la Luz, CC); 7. Museo de Mérida (BA); 8. Ruecas (BA); 9. Cogolludo (Orellana de la Sierra, BA): 10. Hornachuelos (Ribera del Fresno, BA); 11. neretobriga (Frenegal de la Sierra, BA); 12. Castrejón de Capote (Higuera la Real, BA); 13. Badajoz; 14. Museo de Evora; 15. Villanueva del Rio y Minas (SE); 16. Cala (HU); 17. Sotiel Coronada (Valverde del Camino, HU); 18. Córdoba: 19. La Loba (Fuente Obejuna, CO); 20. Diógenes (CR); 21. La Bienvenida (Almodóvar del Campo, CR); 22. Alarcos (CR); 23. Villanueva de la Fuente (CR);24. El Centenillo (J). Para las referencias bibliográficas cf. $\mathrm{n} .45$.

asentamientos prerromanos del sur de la provincia de Badajoz y algunos del territorio onubense. La expansión de los celtiberos hacia el suroeste peninsular es un tema al que en los últimos tiempos se le ha dedicado un especial interés ${ }^{47}$ y dado que el material arqueológico justifica claramente su presencia no vamos a detenernos en ello. La moneda celtibérica en esta región suroccidental reitera siempre un modelo uniforme: presencia poco enérgica pero constante, salvo en el castro de Villasviejas del Tamuja (Botija-Plasenzuela, Cáceres) donde cuenta con un elevado porcentaje, dato que posiblemente deba interpretarse como la documentación de un fenómeno cultural: el desplazamiento de gentes desde Celtiberia hacia tierras extremeñas, bien de forma voluntaria o forzosa debido probablemente a enfrentamientos con Roma, gentes que llevarian consigo sus usos monetales a una zona en la que no existian, llegando a generar emisiones en el nuevo lugar de asentamiento. En estas emisiones se mantuvieron

47 Cf. el reciente trabajo de Berrocal Rangel, L., Los pueblos célticos del suroeste de la P. Ibérica. Madrid, 1992. las mismas características tipológicas del lugar de origen para que fuera comprensible para sus usuarios pero ya aparece un nuevo topónimo en el que se utiliza una grafia propia de la Ulterior. Es más, dada la abundancia de hallazgos en la región extremeña de monedas de la última serie de sekaisa y la semejanza entre estas piezas y las emitidas por tamíusia, cabe preguntarse si son grupos de śekaisa quienes a fines del siglo II a.C. o comienzos del i se trasladan en generaciones sucesivas y se asientan en Villasviejas del Tamuja trayendo consigo el numerario y acuñando poco después con el nuevo topónimo, tamísíia, pero exactamente las mismas características monetales de su ceca de origen. Si fuese así tendríamos que descartar su origen arévaco, propuesto por Garcia-Bellido, y pensar que la grafía del área occidental la aprenden ya en Extremadura. Creemos que asi debe ser interpretada la amonedación de tamuśia, cuya localización en Villasviejas del Tamuja (Botija-Plasenzuela, Cáceres) parece hoy fuera de dudas, y ello justificaría la presencia de esta ceca que, manteniendo unos tipos y leyendas plenamente celtibéricos, se sitúa en territorio considerado hasta hoy como exclusivamente vetón. 

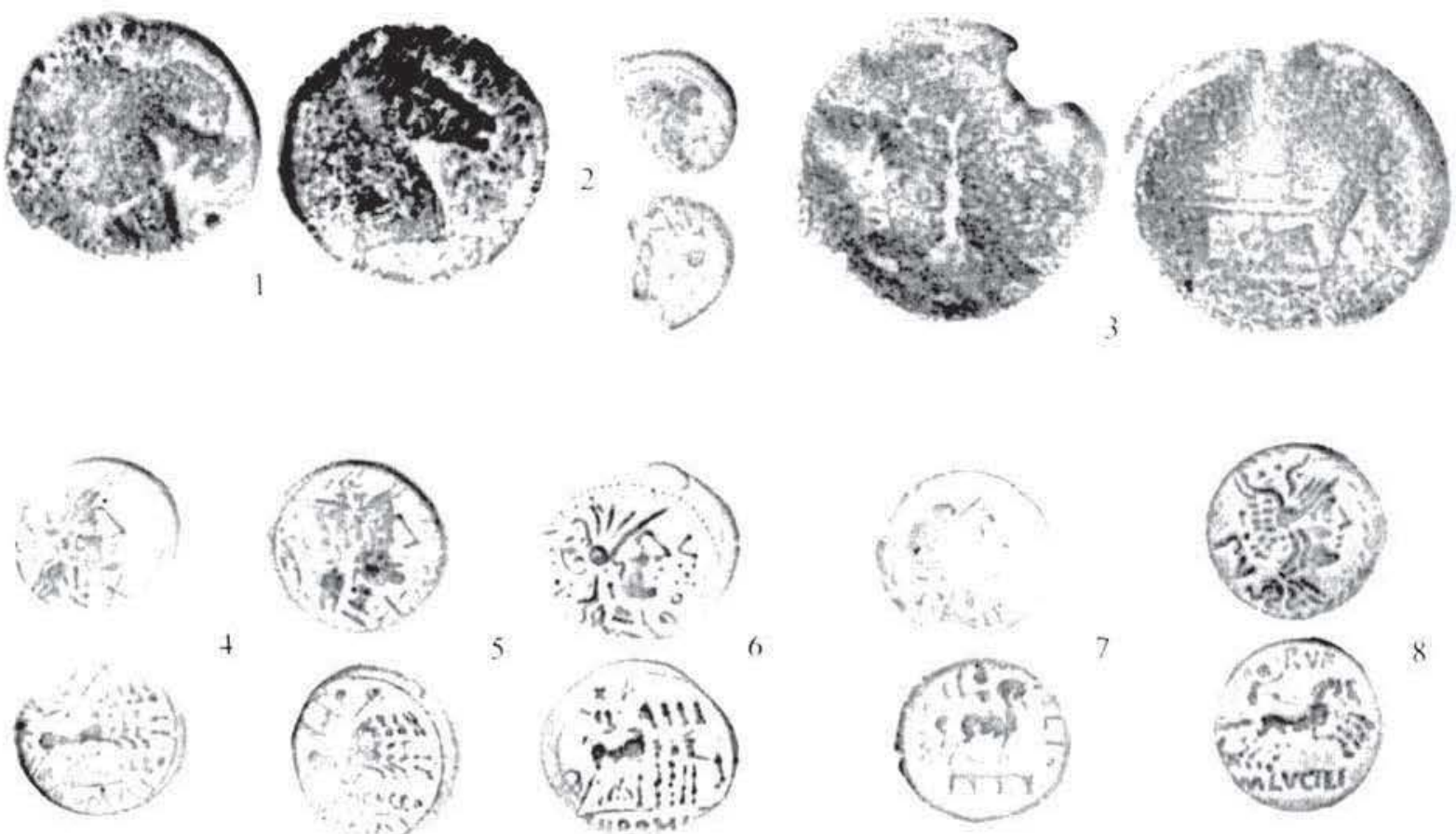

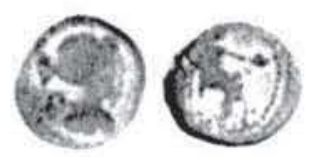

9

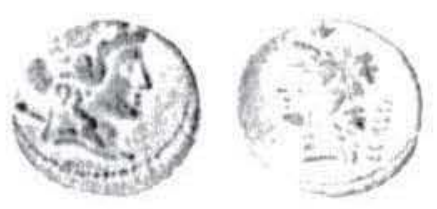

12

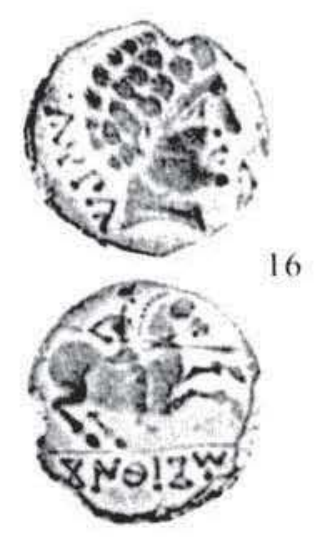

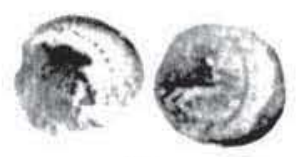

10

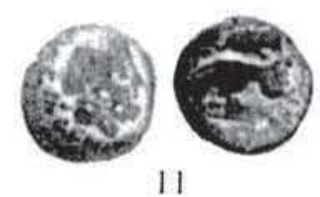

11

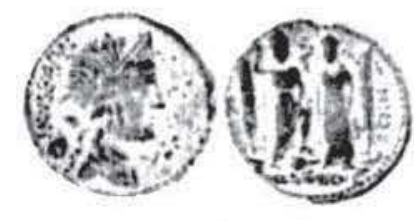

13
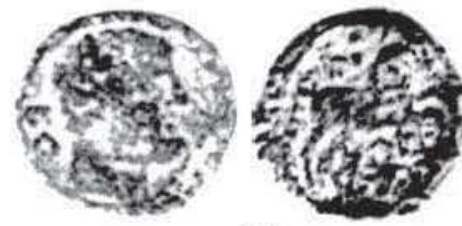

15

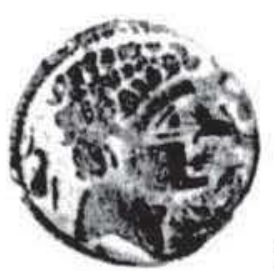

17
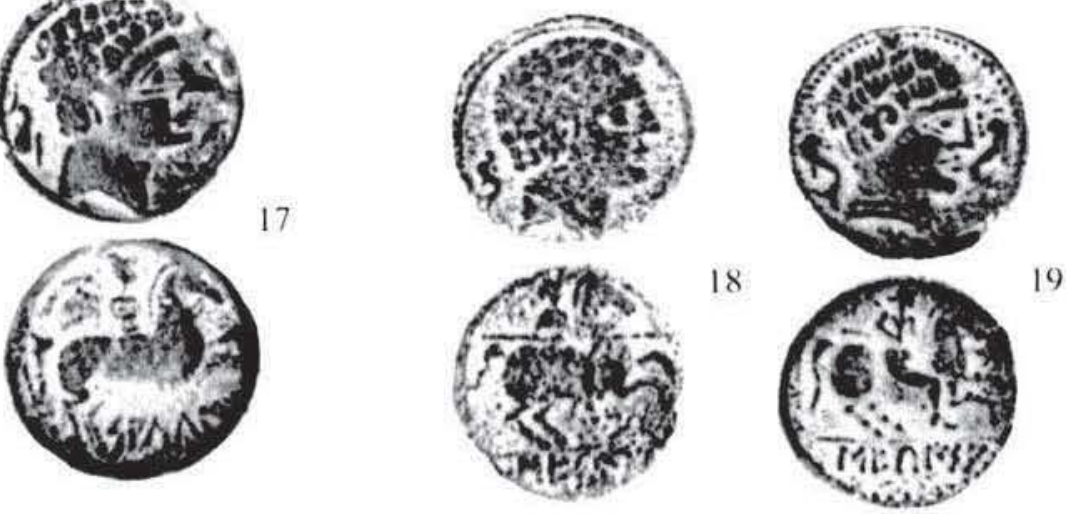

Figura 7.-Conjunto numismático inédito procedente de colecciones particulares de Botija (Cáceres). No fotografiada la pieza n" 14 por su mala conservación. 


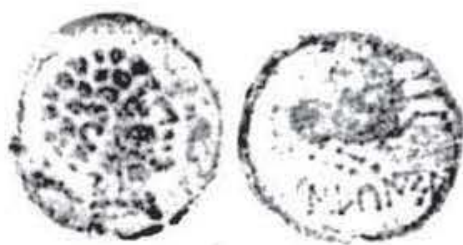

11
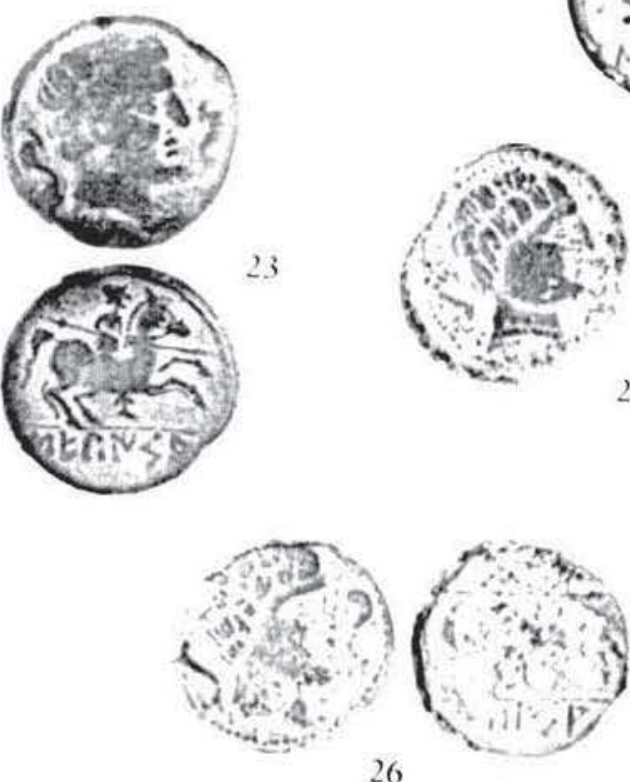

26
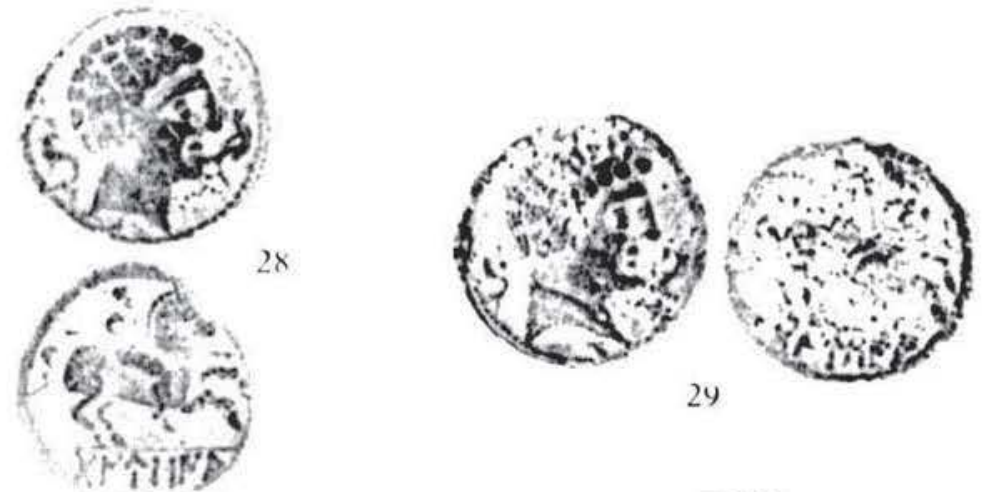

24
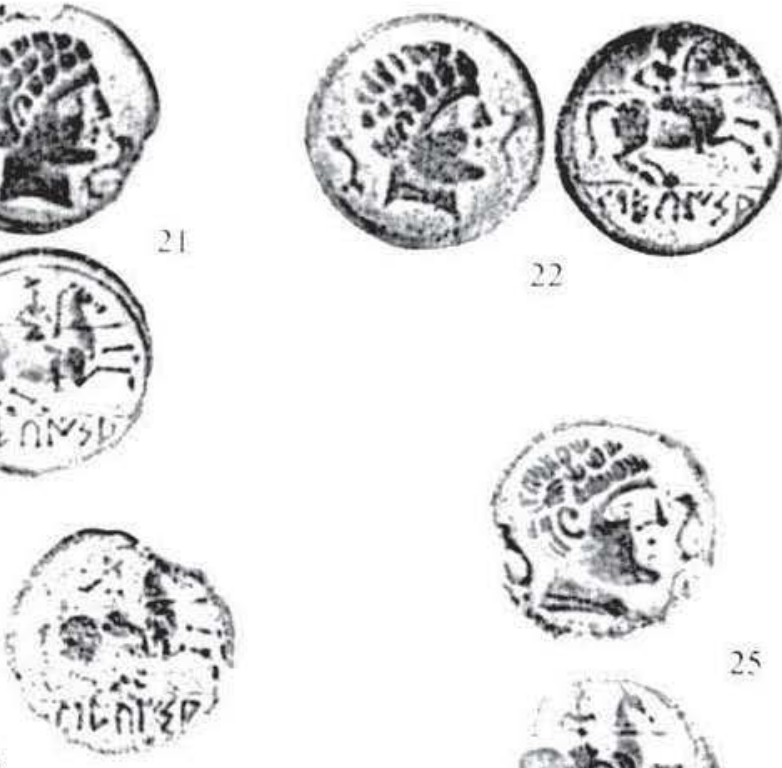

22
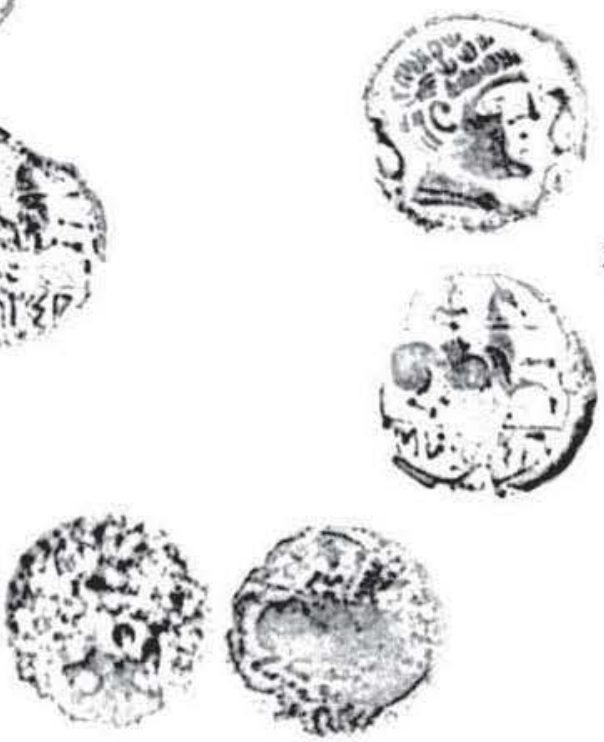

27
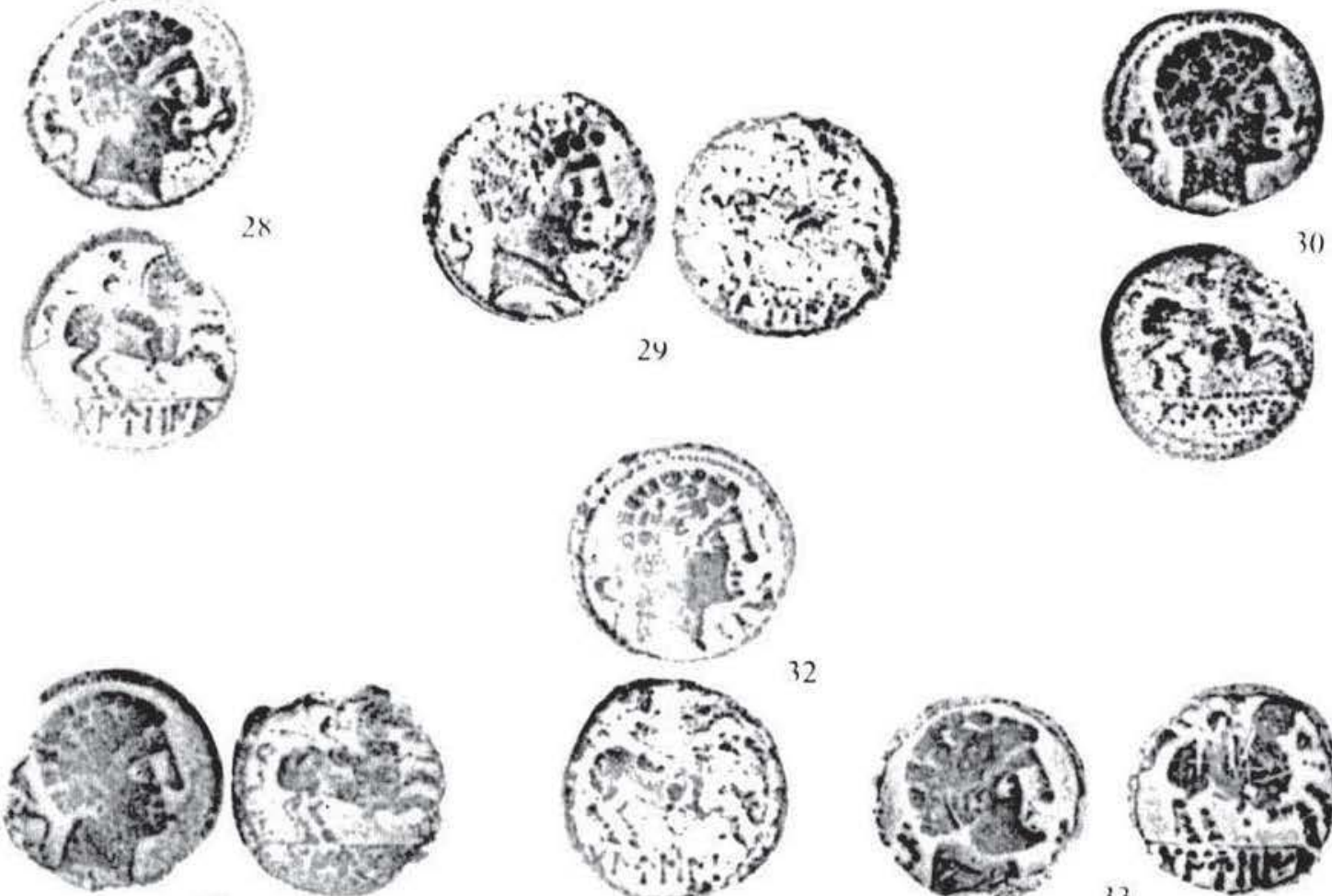

31
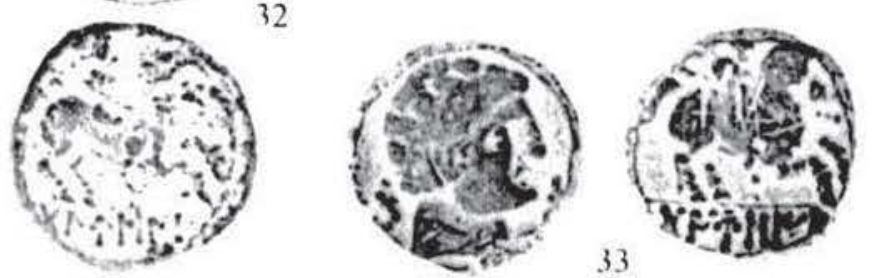

Figura 8.- Conjunto numismático inédito procedente de colecciones particulares de Botija (Cáceres). 

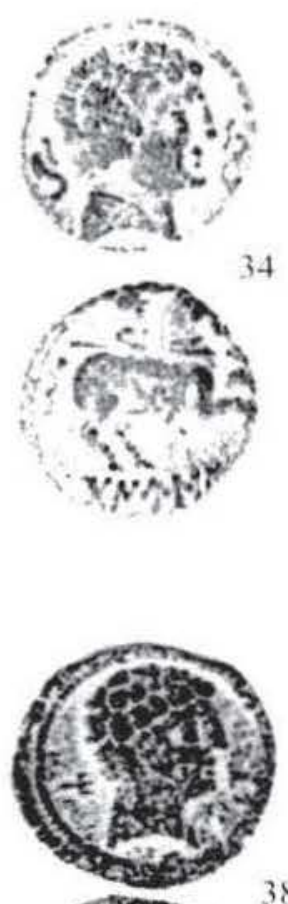

38
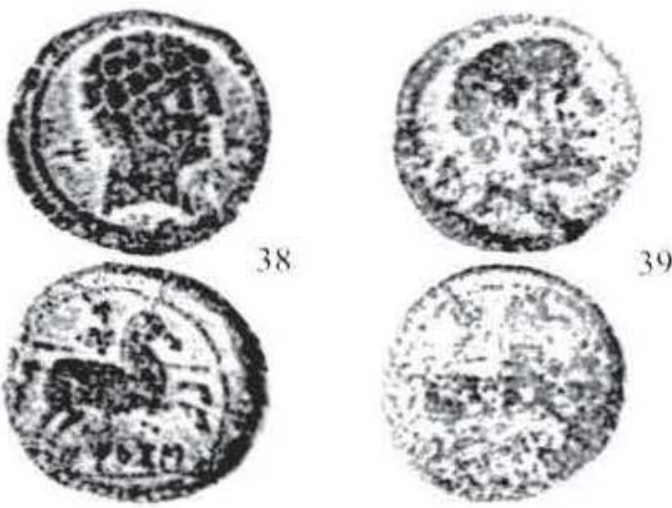

39
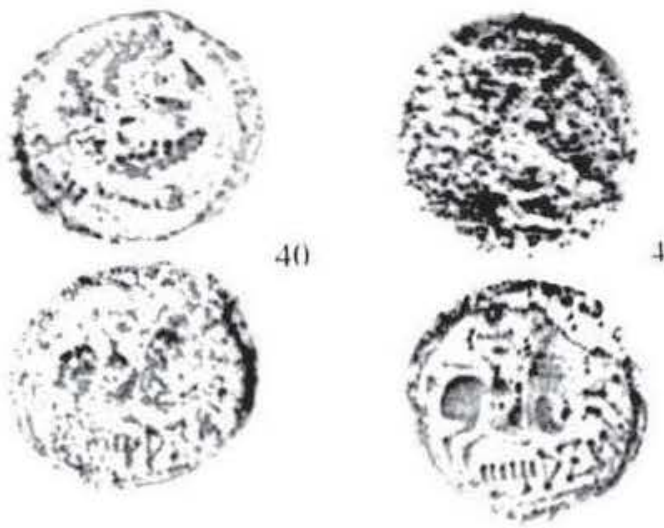

40
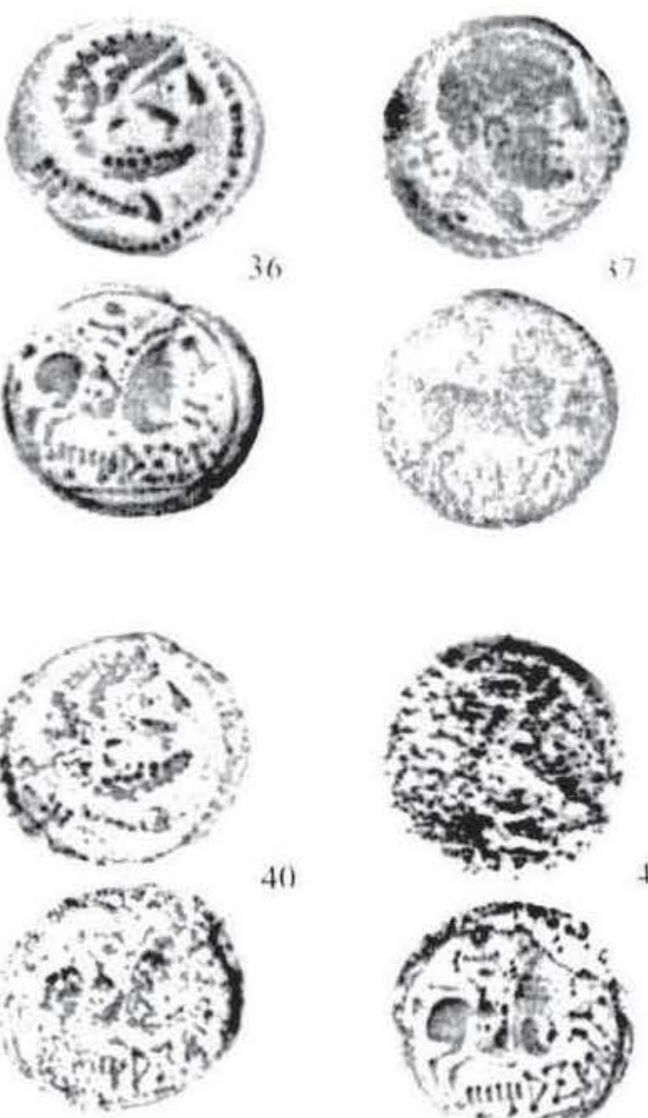

37

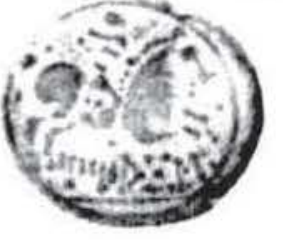

41

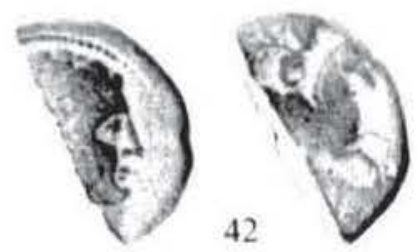

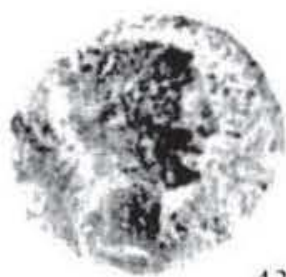

43

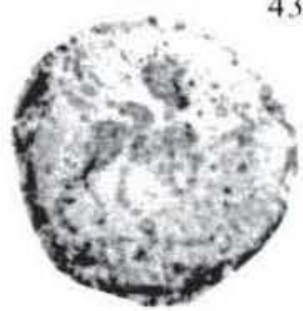

Figura 9.-Conjunto numismático inédito procedente de colecciones particulares de Botija (Cáceres).
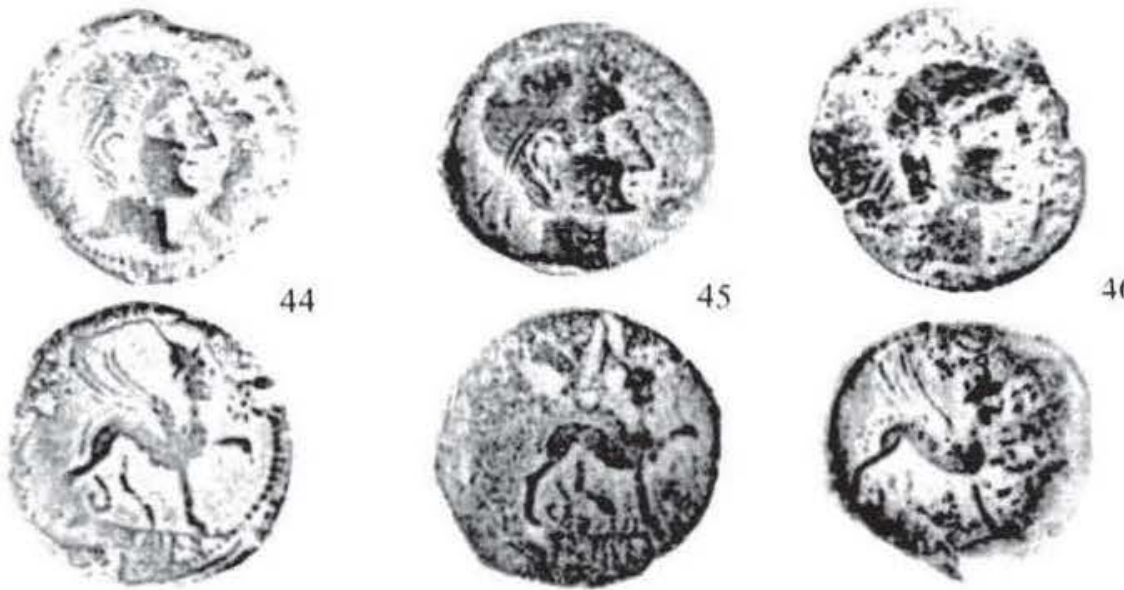

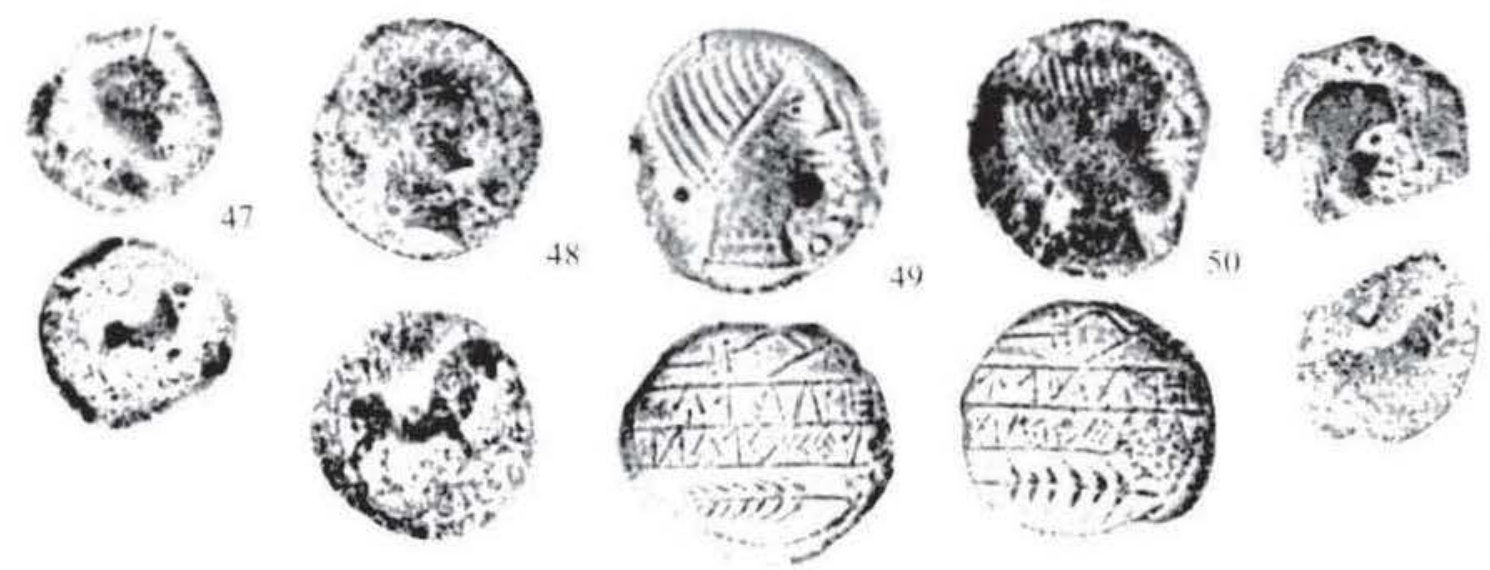

51
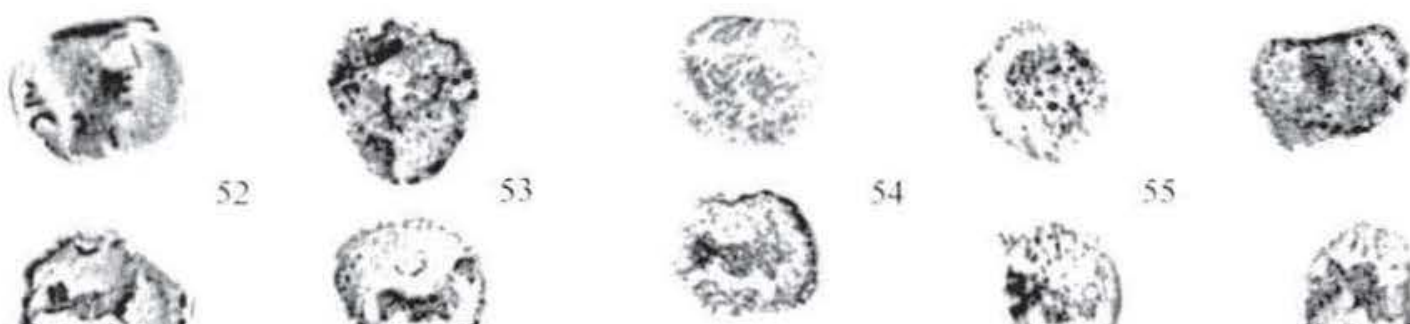

54
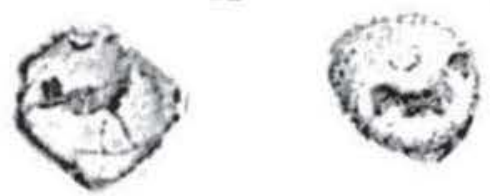

55
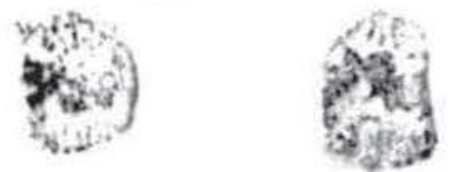

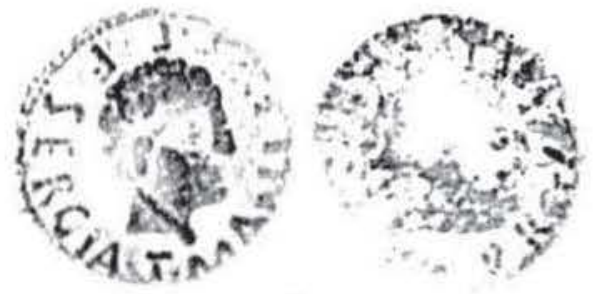

57

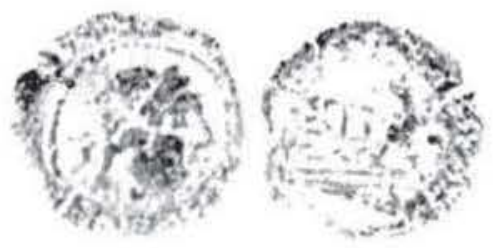

58
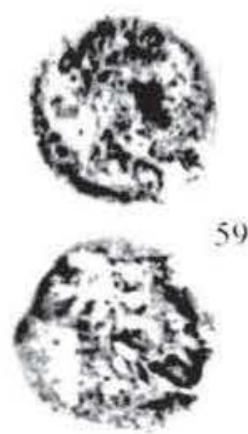
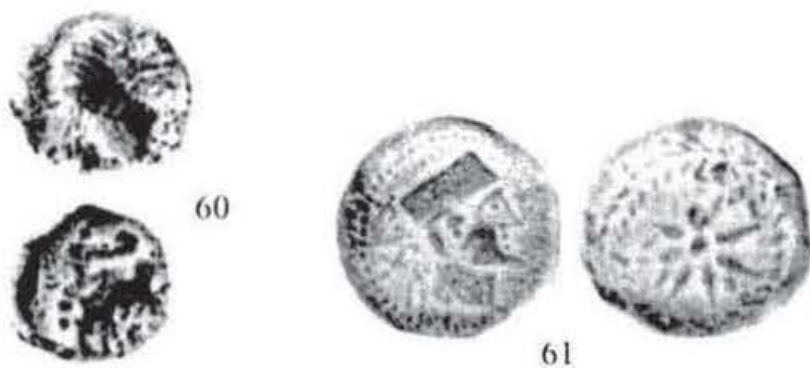

61
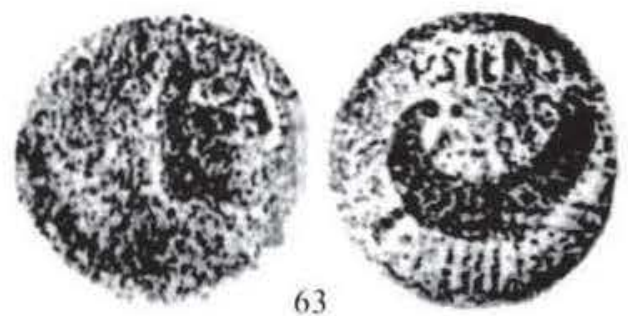

Figura 10, Conjunto numismático inédito procedente de colecciones particulares de Botija (Cáceres). No fotografiada la pieza $n^{\circ} 62$ por su mala conservación. 